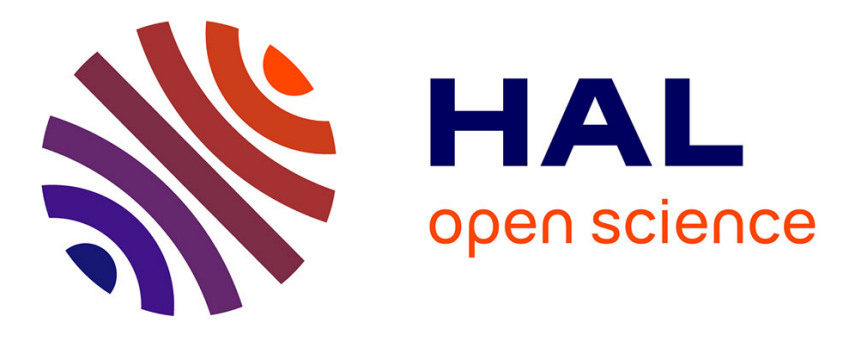

\title{
Les sépultures chasséennes du site de Narbons Montesquieu-de-Lauragais (Haute-Garonne)
}

Yaramila Tchérémissinoff, Hélène Martin, Myriam Texier, Jean Vaquer

\section{To cite this version:}

Yaramila Tchérémissinoff, Hélène Martin, Myriam Texier, Jean Vaquer. Les sépultures chasséennes du site de Narbons Montesquieu-de-Lauragais (Haute-Garonne). Gallia Préhistoire - Archéologie de la France préhistorique, 2005, 47, pp.1-32. 10.3406/galip.2005.2046 . hal-01576793

\section{HAL Id: hal-01576793 \\ https://hal.science/hal-01576793}

Submitted on 24 Aug 2017

HAL is a multi-disciplinary open access archive for the deposit and dissemination of scientific research documents, whether they are published or not. The documents may come from teaching and research institutions in France or abroad, or from public or private research centers.
L'archive ouverte pluridisciplinaire HAL, est destinée au dépôt et à la diffusion de documents scientifiques de niveau recherche, publiés ou non, émanant des établissements d'enseignement et de recherche français ou étrangers, des laboratoires publics ou privés.

\section{(ㅇ)(1) $\$$}

Distributed under a Creative Commons Attribution - NonCommercial - NoDerivatives| 4.0 


\title{
LES SÉPULTURES CHASSÉENNES DU SITE DE NARBONS À MONTESQUIEU-DE-LAURAGAIS (HAUTE-GARONNE)
}

\author{
Yaramila TCHÉRÉmissinoff, Hélène MARTIN, Myriam Texier et Jean VAquer
}

Yaramila TCHÉRÉmISSINOFF : Éditeur scientifique, archéoanthropologie et pratiques funéraires. INRAP Grand Sud-O uest et EHESS, UMR 8555, Base archéologique, ZAC Champs Pinsons, F-31650 Saint-O rens-de-Gameville.

Hélène MARTIN : Étude archéozoologique. INRAP Grand Sud-O uest et UMR 5608, Base archéologique, ZAC Champs Pinsons, F-31650 Saint-O rens-de-Gameville.

Myriam TeXIER : Étude paléobiologique. Laboratoire d'Anthropologie des populations du passé, UMR 5809 du CNRS, Université de Bordeaux-I, avenue des Facultés, F-33405 Talence Cedex.

Jean VAQUER: Étude de la céramique, données typochronologiques, puits et conseil scientifique. Centre d'Anthropologie, U MR 8555, CNRS-EHESS-U PS-Collège de France, 39 allées Jules Guesde, F-31000 Toulouse.

\begin{abstract}
Mots-clés. H auteGaronne, M idi dela France, Chasséen, sépultures, pratiques funéraires, archéozoologie, paléobiologie, puits, amincissement dysplasique de la voûte crânienne.

Résumé. Le site de $\mathrm{N}$ arbons (commune de M ontesquieu-deL Luragais, $\mathrm{H}$ auteG aronne) identifié comme un établissement médiéval a été fouillé en août 1999 dans le cadre de fouilles de sauvetage réalisées par l'AFAN sur le tracé de l'autoroute A 66. Tou tefois six fosses, dont quatre contenaient des sépultures, ont pu être attribuées au N éolithique. Les inhumations se trouvaient dans des creusements asssez profonds, dont les sections étaient majoritairement oblongues ou subrectangulaires. Au cun des individus n'était au contact des fonds, ce qui pose le problème de la destination primaire des structures qui pourraient êre des puits réutilisés à des fins funéraires. Les sédiments dans lesquels se trouvaient les sépultures éaient homogènes, sauf ceux de la fosse cylindrique qui conten ait des rejets à plu sieurs niveaux. On rè̀ve trois sépultures individuelles (un adulte et deux enfants) et une sépulture double d'adultes qui ont été déposés simultanément ou dans un laps de temps très court eq qui pourraient être apparentés en raison de la constatation sur les deux sujets d'une anomalie, peutêtre d'origine génétique (amincissement dysplasique de la voûte crânienne). Tous les individus présentaient des inflexions plus ou moins marquées des membres, mais les positions sont assez variées. Les données ostéologiques et sédimentaires témoignent plutôt en faveur d'une décomposition des corps en espace confiné C'est indéniablement le cas pour la sépulture double dont la disposition des os implique un système de protection. Aucun élément de mobilier n'apparaît de façon évidente comme une offrande, mais les ééments associés ou dissociés ont parfois fait l'objet d'agen cements particuliers. La majorité des comblements s'étant mis en place rapidement, on ne peut rejeter totalement la possibilité d'une relation d'ordre symbolique entre ces ééments et la mise en place des défunts au moment de la condamnation des structures. Les datations absolues et, dans un cas, le mobilier associé révèlent que ce petit ensemble appartient au N éolithique moyen ; trois sépultures sont à placer au début du Chasséen, alors qu'une autre appartient incontestablement à l'éape finale de cette culture.
\end{abstract}

Key-words. H auteGaronne, South of France, Chassean, burials, funerary practices, archaeozoology, paleobiology, wells, displasic thinning of the dome of the skull.

Abstract. The site of $\mathrm{N}$ arbons (township of M ontesquieu-deL aurageais, $\mathrm{H}$ auteGaronne), identified as a medieval area was excavated in August 1999 in the setting of preventive excavations carried out by the AFAN on the tracing of the A 66 freway. Therefore, six pits are attributed to the $\mathrm{N}$ eolithic and four of them were containing bu rials. These burials set in holes of great depth, whose sections were principally oblong or sub-rectangular. It appears that these structures might be some well reu sed as graves because none of the skeleton was in contact with the funds. $\mathrm{H}$ ence, the primary destination of these stuctures could be reconsidered. The sediments on which they have been 
placed were extremely homogeneous except the filling of the single cylindrical pit which could be in relation with dumps at several layers. One raises three individual burials (an adult and two children) and two adults laid out simultan eously or in a very short time lapse and might be related because of an anomaly noted on the two subjects which could be of genetic origin (displasic thinning of the dome of the skull). All the individuals attested more or less inflections of the members, but the positions presented some variation s. Osteologic and sedimentary data certify rather in favour of decomposition in to a confined space. It's indoubtely the case for the two adults whose bones disposition implies a cover system. None item appears clearly as an offering, but some other pieces, dissociated, had been the object of particular settings. The majority of the fillings being set up quickly, one cannot reject the possibility of a completely symbolic order relation between these elements and bu rials during the sealing of the structures. The radiocarbon datations added to the typology of artefacts in one case reveal that this group belongs to the $\mathrm{M}$ iddle $\mathrm{N}$ eolithic. Three burials should be dated to the begen ing of Chassean, whereas one belongs at the end of this culture

Translated by Yann BeLIEZ

Palabras claves. H aute Garonne, Sur de Francia, Chasense, sepulturas, prácticas fun erarias, aqu eozoología, paleobiología, pozos, adelgazamien to displático de la bóveda craneana.

Resumen. Identificado como un asentamiento medieval, el sitio de $\mathrm{N}$ arbons (municipio de M ontesquieu-deL auragais, $\mathrm{H}$ auteG aronne) fue exvavado en agosto de 1999 en el marco de una rescate llevado a cabo por la AFAN en el trazo de la autopista A66. Sin embargo, estos trabajos revelaron seis fosas fechadas del neolítico en tre las cuales cuatro contenían sepulturas. Las inhu maciones se en contraban en hoyos muy profundos cuyos perfiles son principalmente oblongo o sub-rectangular. Ningún sujeto estaba en contacto directo con el fon do de la fosa, lo que plantea el problema del uso original de estas estructuras que podrían ser pozos reutilizados como sepulcros. Los sedimentos en los cuales se en contraban las inhumaciones eran homogéneos, salvo en el caso de la fosa cilíndrica que contenía desechos en varios niveles.

Contamos con tres sepulturas individuales (un adulto y dos niños) y una sepultura doble de adultos que fueron colocados de forma simultánea 0 en un plazo de tiempo muy breve. Estos podrían tener alguna relación de parentesco ya que ambos muestran una anomalía de posible origen genético (adelgazamiento displático de la bóveda craneana).

Todos los in dividuos muestran flexiones mas o men os marcadas a nivel de los miembros aunque presentan posiciones bastante variadas. L os datos osteológicos y sedimentarios apuntan más bien hacia una descomposición en espacio vacío. Es evidente en el caso de la sepultura doble en la cual la distribución de los huesos implica un sistema de protección. No se localizaron artefactos que podrían interpretarse como ofrendas. Sin embargo, los elementos asociados o disociados a veces parecen acomodados. Dado que el rellenamien to de la fosa occurrió segu ramente de forma rápida, hay que contemplar la posibilidad de que exista una relación simbólica entre estos elementos y el depósito de los muertos cuando se clausuraron las fosas. Los fechamien tos absolutos y los artefactos asociados (en un caso) demuestran que este pequeño conjunto perten ece al Neolítico medio. Tres sepulturas son atribuibles a la cultura Chasense mientras que la otra se relacionaría a la etapa final dela misma entidad.

Traducido por G regory PEREIRA

Dans le bassin supérieur de la Garonne, le Néolithique moyen est surtout représenté par la culture chasséenne. Si la définition du faciès régional de cette culture repose sur de nombreux sites d'habitat (Vaquer, 1991), le fait sépulcral est en revanche mal connu. À I'heure actuelle, ce sont les sites de Villeneuve-Tolosane et Cugnaux, près de Toulouse (17 sépultures) et de Saint-Michel-du-Touch (2 sépultures) qui ont livré les ensembles funéraires les mieux documentés. Ces sites révèlent une assez grande diversité de pratiques funéraires, qui se manifeste à la fois dans les types de structures utilisées (réutilisation de silos, de fosses ou de souterrain, implantation fréquente dans les fossés d'enceintes, tombes en fosses, monument de grande envergure), dans les modes de dépôts - primaires, en ambiance colmatée, confinée ou vide, voire secondaire - ainsi que dans la présence et la richesse des équipements et offrandes ou dans leur caractère plus ou moins ostentatoire. Les faits récurrents sont une localisation des tombes au sein des habitats ou à proximité et une prédominance de l'inhumation individuelle en position fléchie. Si on agrandit le cadre de comparaison au Languedoc-Roussillon et à la Catalogne, la diversité ne fait que s'accroître, car en plus des mêmes types de structures funéraires on rencontre aussi des tombes à appareillage lithique construites au-dessus du sol ou enfouies, des proto-hypogées et d'autres modes de traitement des cadavres, incinérés ou déposés dans des cavités karstiques ou artificielles (Vaquer, 1998). Cette forte variabilité a sans doute des causes multiples: interférences culturelles entre le domaine languedocien du Chasséen et celui du Montbolo ou des sepulcros de fosa de Catalogne, faible 
nombre de sépultures pour une très longue durée, de l'ordre du millénaire, mais aussi certainement traitement différencié en fonction du mode de vie, des circonstances ou des causes du décès, du contexte environnemental et du statut social, paramètres qui ne sont pas toujours discernables loin s'en faut et qui justifient un approfondissement des analyses. La découverte de quatre nouvelles sépultures sur le site de Narbons et la possibilité d'en réaliser une étude croisant les approches archéologique, chronométrique, anthropologique et archéozoologique apportent des informations qualitatives qui suscitent un réexamen de certaines de ces problématiques.

\section{PRÉSENTATION DU SITE ET DES DÉCOUVERTES}

\section{CIRCONSTANCE DE LA DÉCOUVERTE}

Le site de $N$ arbons a été découvert dans le cadre du diagnostic AFAN réalisé sur le tracé de l'autoroute A 66, au mois de février 1999. Identifié comme un établissement médiéval, sa fouille préventive a été confiée à $F$. Guédon en août de la même année. L'opération a révélé plus de 120 structures en creux ( silos, fours, trous de poteau, fossés) datées entre le IX ${ }^{\mathrm{e}}$ et les XI-XII'e siècles (Guédon, 1999). C'est à la fin de cette opération qu'a été mis au jour l'essentiel des structures néolithiques, une sépulture, identifiée comme chasséenne (st. 1020) ayant précédemment été prélevée par les soins de B. Boisseau. À la demande conjointe de cette collègue, de F. Guédon et de J.-C. Bats (coordinateur AFAN pour I'A 66), I'une d'entre-nous ${ }^{1}$ est intervenue afin d'encadrer la fouille de deux autres sépultures néolithiques (dont une double). Pendant cette intervention, une quatrième sépulture et deux dépôts d'animaux complets en connexion ont aussi été découverts. Cet ensemble a déjà fait l'objet d'une note (Tchérémissinoff et collab., 2000), ainsi que d'une communication d'actualité (Tchérémissinoff, 2003a) ${ }^{2}$.

\section{LOCALISATION DU SITE ET DES STRUCTURES}

Le site de $\mathrm{N}$ arbons était localisé à $2 \mathrm{~km}$ au sud-est de Montesquieu-de-Lauragais (Haute-Garonne). II était

\section{Yaramila Tchérémissinoff.}

2. Le présent article a pu être réalisé grâce à l'obtention d'un crédit " d'aide à la publication » accordé par la sous-direction de l'Archéologie. implanté au sommet d'une colline du Lauragais, qui domine la plaine alluviale de l'H ers-Mort, à une trentaine de kilomètres au sudest de Toulouse (fig. 1). Ce point haut est entaillé au nord-est par le long versant encadrant cette vallée et à l'est par un petit vallon sec. Le substrat est constitué par des molasses, qui sont des faciès sédimentaires très sensibles à l'érosion. Ce substrat était recouvert d'un horizon labouré d'environ 0,4 $\mathrm{m}$, de nature essentiellement argileuse.

Six fosses ont été reconnues comme néolithiques. Q uatre d'entre elles contenaient des défunts: les structures 1020, 1034, 3067 et 4000 (une sépulture double). Les deux autres fosses, 3035 et 4002 , ont été attribuées à cette période sur la base de leur morphologie et des dépôts particuliers qu'elles contenaient. Les structures étaient implantées sur la partie haute du site et réparties sur une surface d'environ $1000 \mathrm{~m}^{2}$. Les distances qui les séparaient étaient très variables, d'une dizaine à une cinquantaine de mètres (fig. 2).

\section{DESCRIPTION DES STRUCTURES, DES SÉPULTURES ET DES ASSEM BLAGES}

\section{LA FO SSE 3035}

Cette fosse présentait un plan oblong de 1 sur $1,3 \mathrm{~m}$ et une profondeur conservée d'environ $1,7 \mathrm{~m}$ (fig. 3). Les parois étaient légèrement évasées mais on observait un rétrécissement dans le quart inférieur, dont le plan était plutôt rectangulaire. Les séquences de comblement, composées d'un sédiment argilo-sableux étaient assez homogènes (US 1 et 2). La portion supérieure de la fosse était cependant plus riche en charbons. Dans ce niveau et au centre se trouvait une meule entière plate, en grès à ciment calcaire de type néolithique. On observait aussi de légers nappages d'éléments calcaires concrétionnés (US 3 et 4) à la hauteur du rétrécissement des parois. Le niveau US 1 a livré également une portion d'hémi-mandibule gauche de cerf, portant les trois molaires peu usées.

\section{LA FO SSE 4002}

La fosse présentait un plan subrectangulaire de $0,7 \mathrm{~m}$ sur $1,2 \mathrm{~m}$ et une profondeur conservée de $1,1 \mathrm{~m}$ (fig. 4). Le comblement argilo-sableux était très homogène, mais on notait une plus grande densité d'escargots dans le tiers inférieur. Les parois du tiers supérieur étaient un peu 


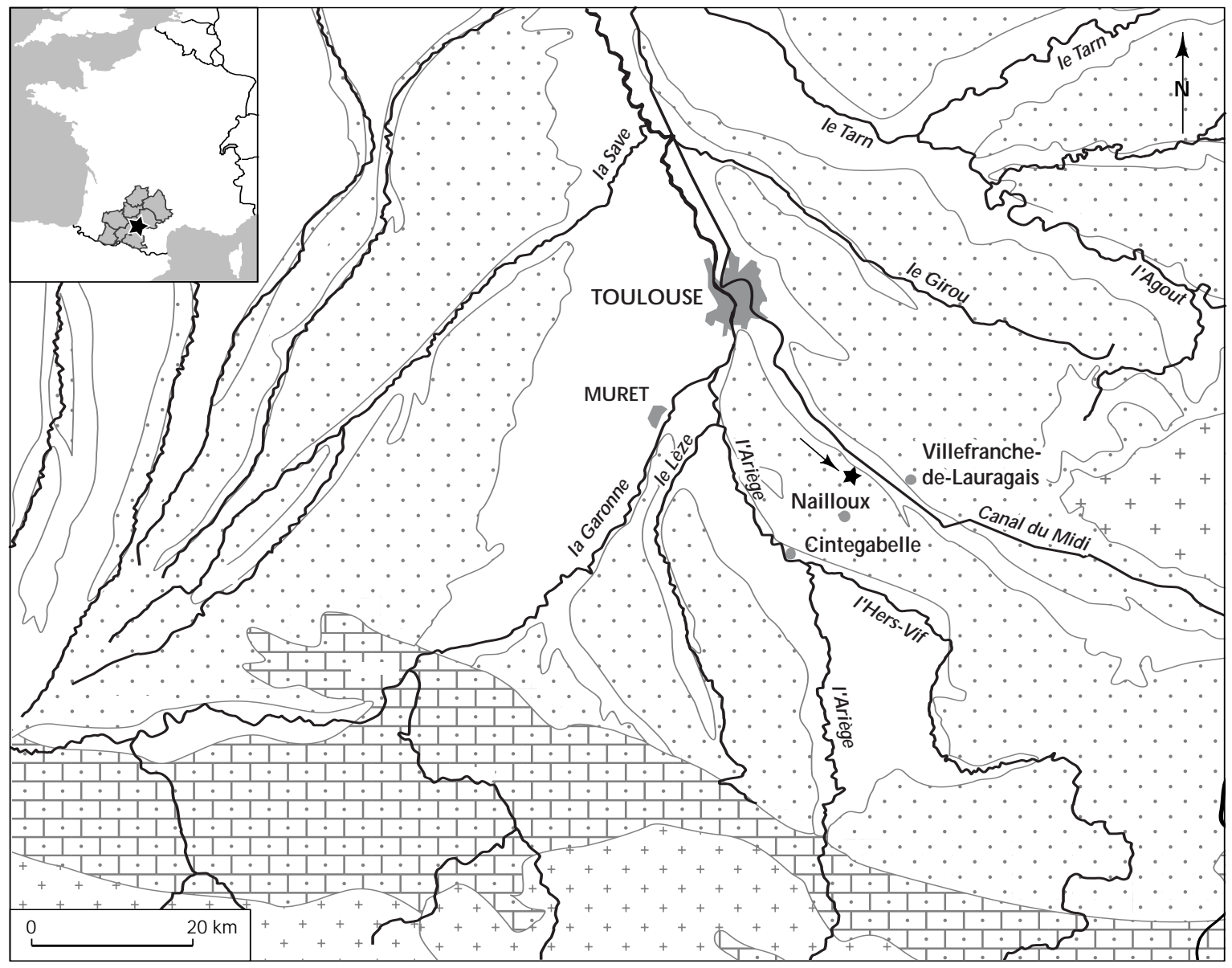

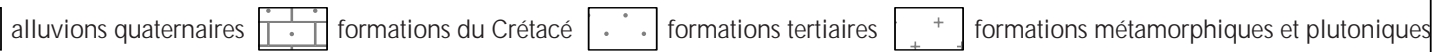

Fig. 1 - Localisation du site de Narbons (infographie L. L oiselier, M. Jarry, INRAP).

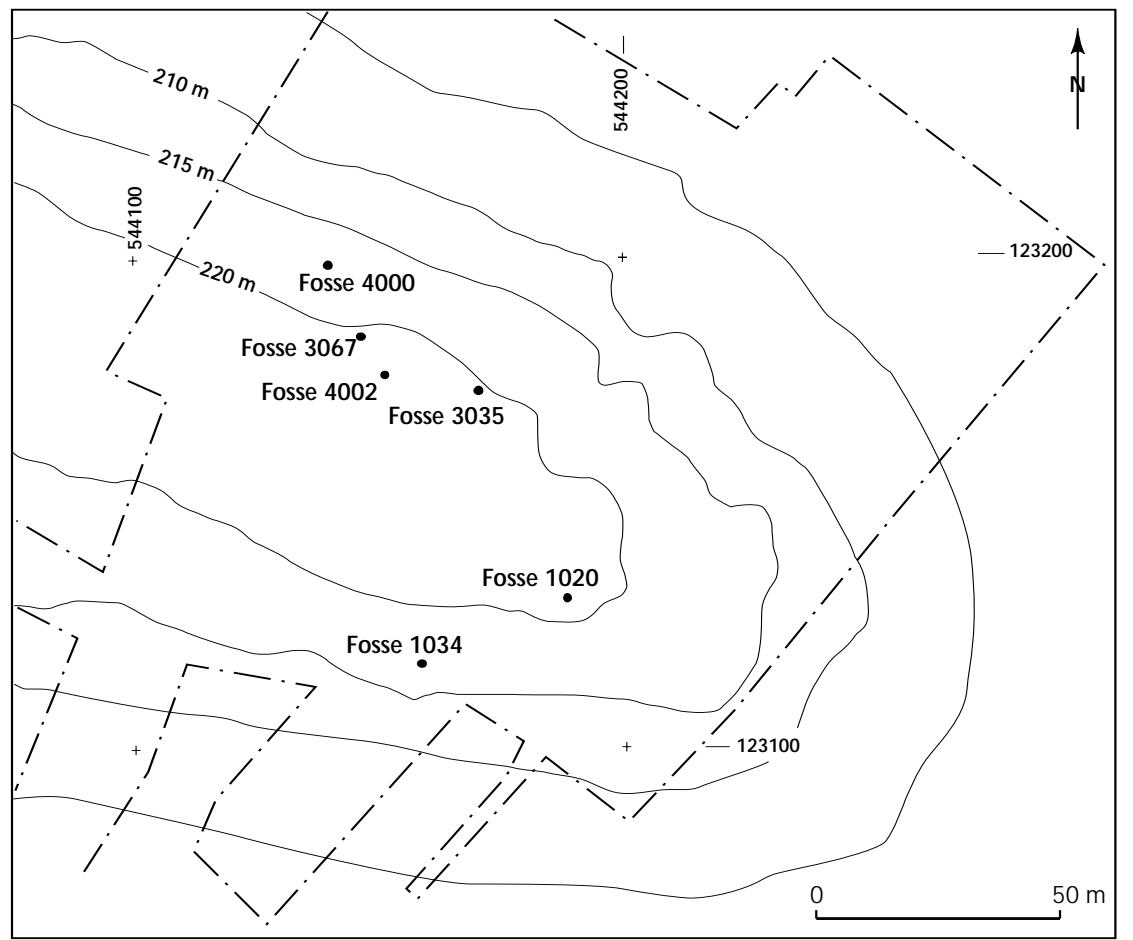

Fig. 2 - Localisation des structures (infographie L. Loiselier, M. Jarry, INRAP). 

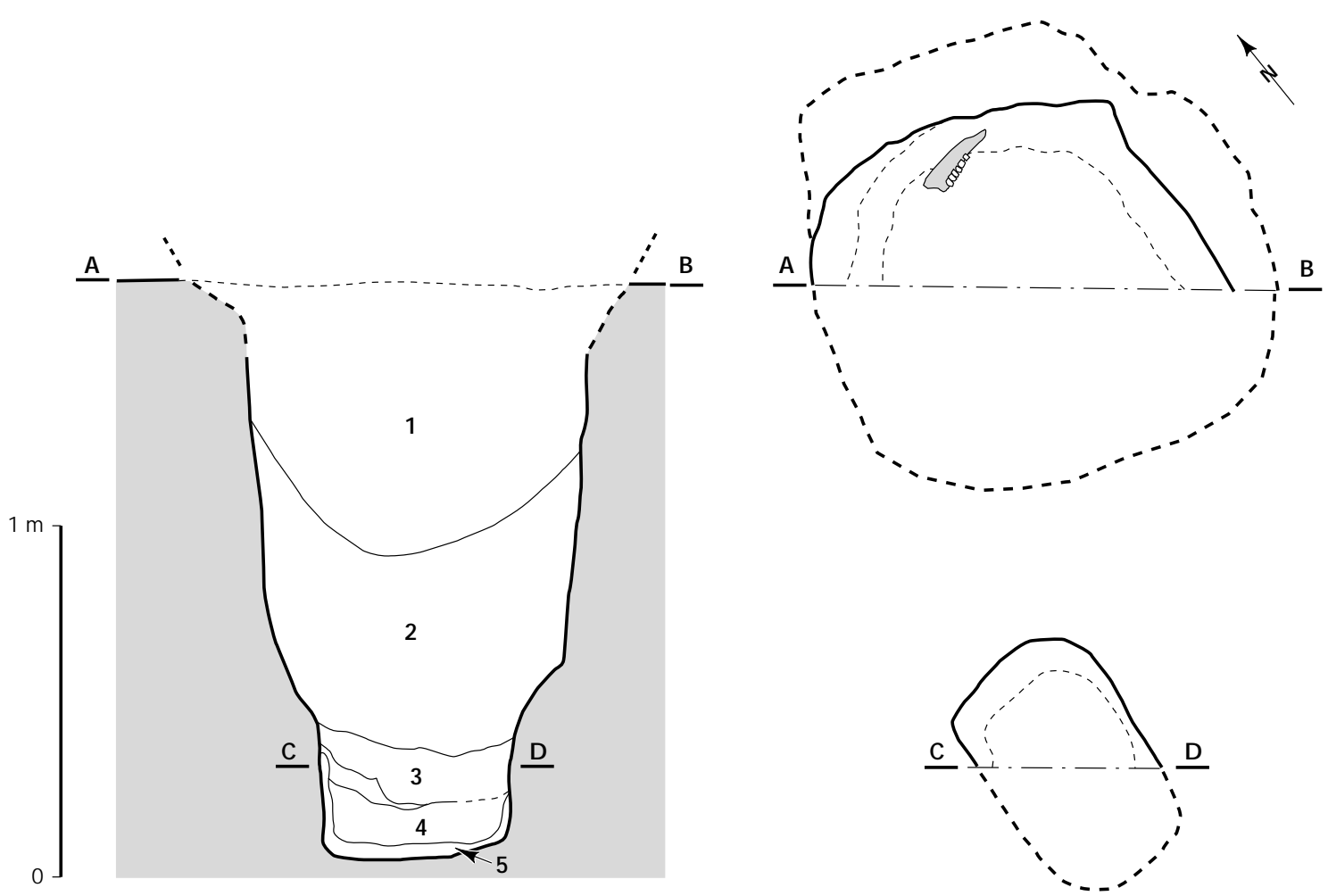

Fig. 3 - La fosse 3035 (dessin C. Vallet; infographie L. Loiselier, INRAP).
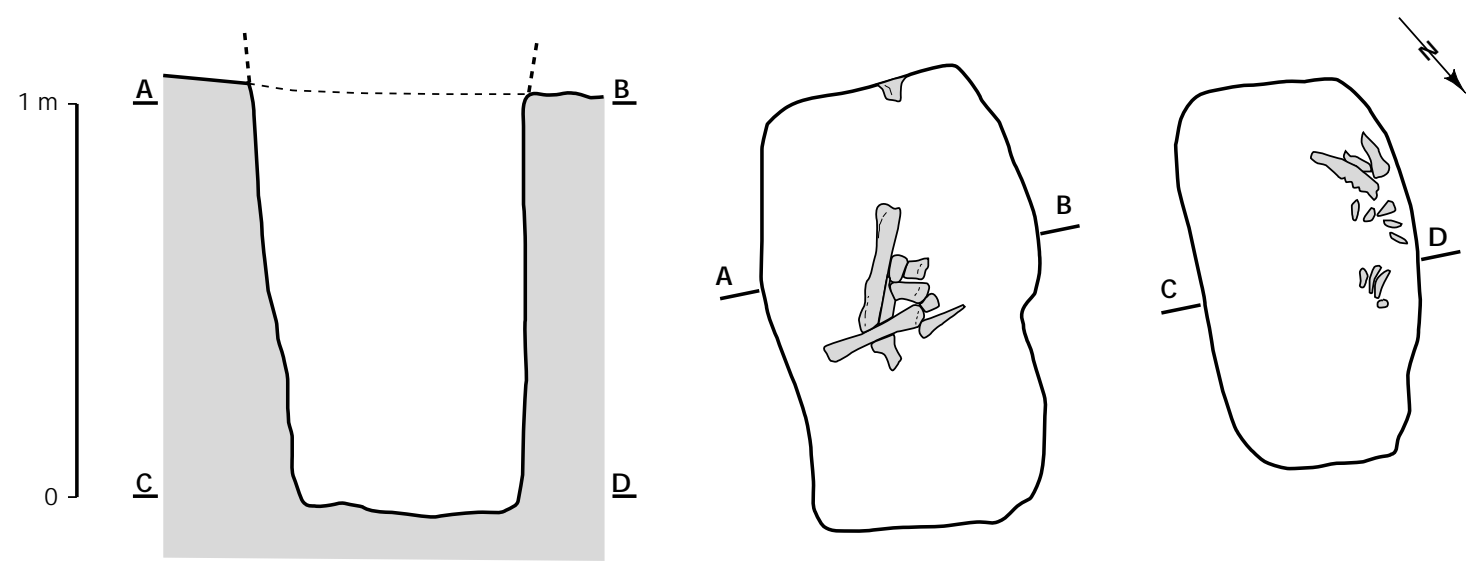

Fig. 4 - La fosse 4002 (dessin C. Vallet; infographie L. L oiselier, INRAP).

évasées, mais très verticales sur les deux tiers inférieurs; cette portion présentait ainsi un plan davantage rectangulaire. C'est à hauteur de cette variation et au centre de la fosse qu'étaient groupés les restes de boviné. II s'agit de certains éléments d'une patte postérieure droite (un fémur dont les épiphyses ne sont pas soudées, une patella, un tibia dont l'épiphyse proximale n'est pas soudée, un os malléo- laire, un talus, un calcanéus, une portion de coxal, ainsi qu'une diaphyse de fémur droit) d'un juvénile âgé de moins de 36 mois. C. Vallet (in Guédon, Vallet, 1999), signale que « les os les plus petits étaient rangés en tas sous ou le long des diaphyses du fémur et du tibia » droits. Selon cet auteur, cette disposition en tas correspond à un regroupement volontaire. En effet, il ne s'agit pas d'une patte complète en 
connexion (absence du métapode et des autres os du tarse), mais d'un probable « rejet de boucherie », après dépeçage et désarticulation tels que ceux attestés dans certains dépôts chasséens comme celui de la fosse N13-3 de VilleneuveTolosane où il y avait les membres de 25 bovins. Ils étaient décharnés et présentaient des traces de chauffe qui témoigneraient, dans ce cas, d'un abattage et d'une consommation massive cérémonielle (Geddes et al., 1987).

Des restes de suidés ont été trouvés; à l'exception d'une portion de scapula attribuable à un adulte, ils se rapportent tous à un suidé infantile âgé de moins de 3 mois. C. Vallet signale que ce spécimen a été découvert sur le fond de la fosse, dans la partie ouest, « couché sur le flanc droit, le long de la paroi ».

\section{LA FO SSE ET LA SÉPULTURE 1034}

\section{Morphologie et COMblement de LA Structure}

La fosse présentait un plan subquadrangulaire d'environ $0,9 \mathrm{~m}$ sur $1,2 \mathrm{~m}$ et une profondeur conservée d'environ 1,5 m (fig. 5). Les parois étaient légèrement évasées dans la moitié supérieure, mais très verticales dans la moitié inférieure, qui présentait ainsi un plan davantage rectangulaire. Ces variations morphologiques correspondaient à deux dynamiques de remplissage distinctes. La base contenait un sédiment argilo-sableux très homogène (US 5). À mihauteur de la fosse, c'est le tiers supérieur de ce niveau qui contenait une portion de bois de cerf, puis les os appartenant à un jeune enfant. Le comblement supérieur était de même texture, mais il recelait de nombreux petits charbons (US 2 et 3). Les parois étaient tapissées d'un sédiment comportant de nombreux petits nodules calcaires indurés (US 4). Sa limite inférieure, très horizontale, marquait la zone de contact entre les deux principales séquences. Au centre et au sommet de la fosse, une " cuvette » d'un diamètre d'environ $0,6 \mathrm{~m}$ et d'une profondeur conservée de 0,4 m était comblée d'un sédiment de couleur plus foncée (US 1).

\section{LA SÉPULTURE}

La sépulture 1034 est celle d'un jeune enfant décédé aux alentours d'un an. Le squelette a été très abîmé, en fait la partie inférieure du squelette a été détruite lors du sondage d'évaluation (fig. 6). Ne demeuraient que le crâne, la mandibule, quelques hémi-arcs neuraux cervicaux et thoraciques, quelques côtes droites et gauches, des éléments de la
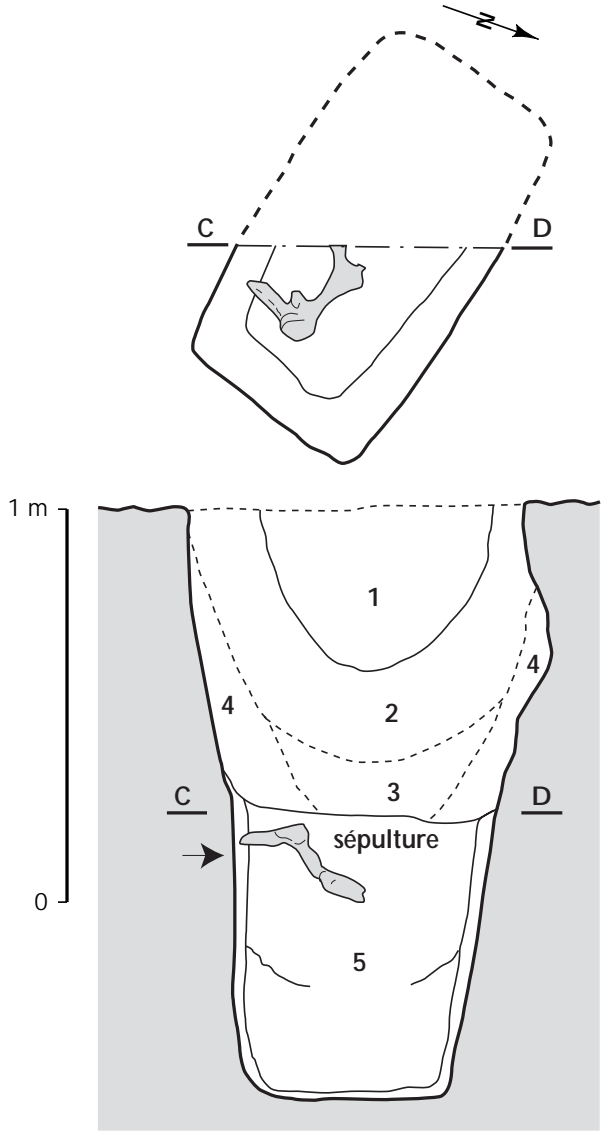

Fig. 5 - La fosse 1034 (dessin C. Vallet; infographie L. Loiselier, INRAP).

ceinture thoracique, I'humérus gauche, I'ulna gauche et un fragment de fibula gauche. L'individu reposait sur le côté gauche, dans un axe ouest-est, tête à l'ouest.

Le faible nombre de pièces ainsi que leur état de conservation limitent les possibilités de lecture. De plus, les déplacements osseux ne semblent pas s'ordonner entre eux et leur incohérence est peut-être imputable à l'activité de fouisseurs (fig. 7). En effet, le crâne se présentait en vue latérale droite, de même que les éléments de la mandibule, encore en relation. Mais les éléments de l'atlas avaient migré à plus de $5 \mathrm{~cm}$, notamment l'hémi-arc droit qui se trouvait à $7 \mathrm{~cm}$ à l'est, sous la scapula droite. Quelques éléments des vertèbres cervicales et thoraciques, déconnectés, se retrouvaient de part et d'autre de l'axe rachidien. Les côtes étaient dispersées, certaines d'entre elles se trouvaient même engagées sous l'occipital droit. La scapula droite apparaissait en vue postérieure, à proximité de sa situation logique, mais ne reposait sur aucune côte droite. L'autre 

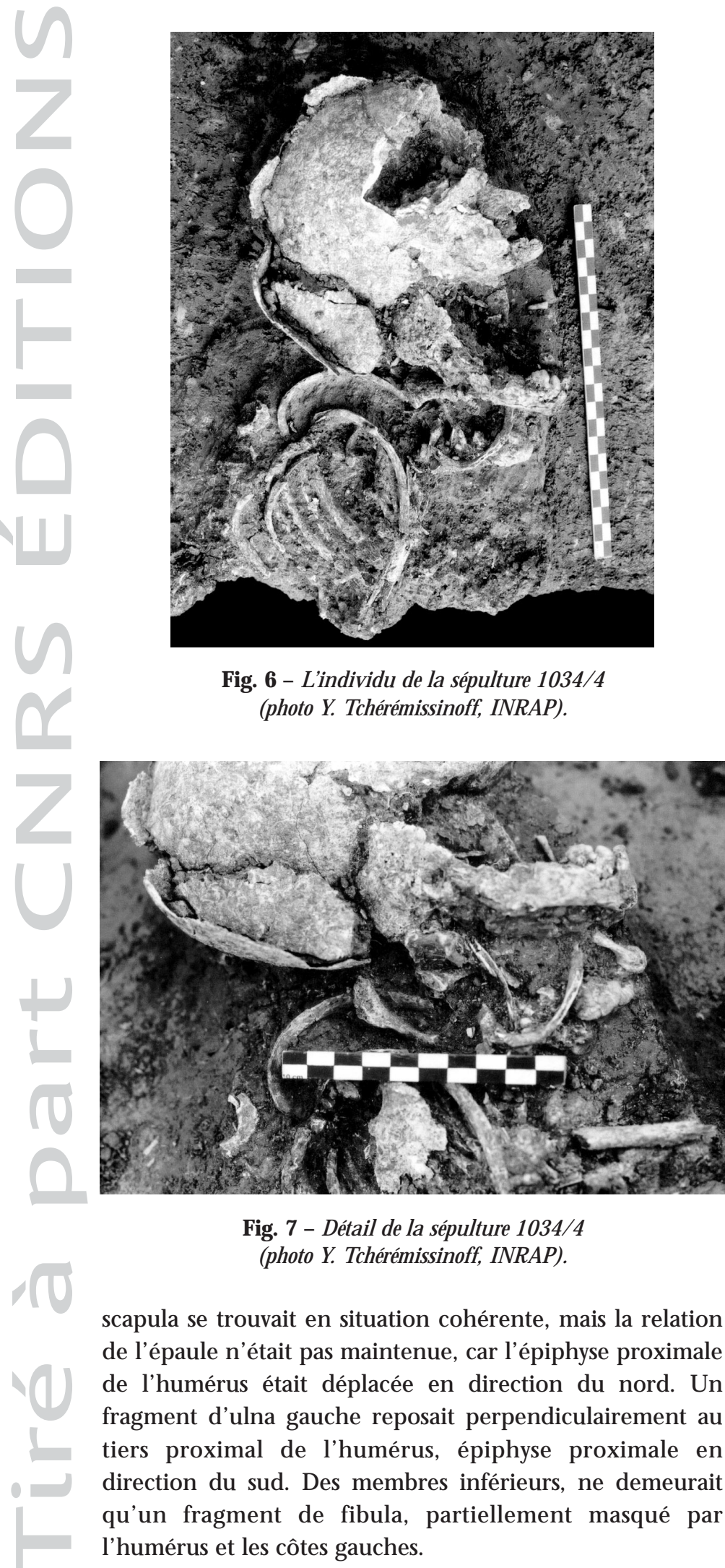

Fig. 7 - Détail de la sépulture 1034/ 4 (photo Y. Tchérémissin off, INRAP).

scapula se trouvait en situation cohérente, mais la relation de l'épaule n'était pas maintenue, car l'épiphyse proximale de I'humérus était déplacée en direction du nord. Un fragment d'ulna gauche reposait perpendiculairement au tiers proximal de l'humérus, épiphyse proximale en direction du sud. Des membres inférieurs, ne demeurait qu'un fragment de fibula, partiellement masqué par l'humérus et les côtes gauches.

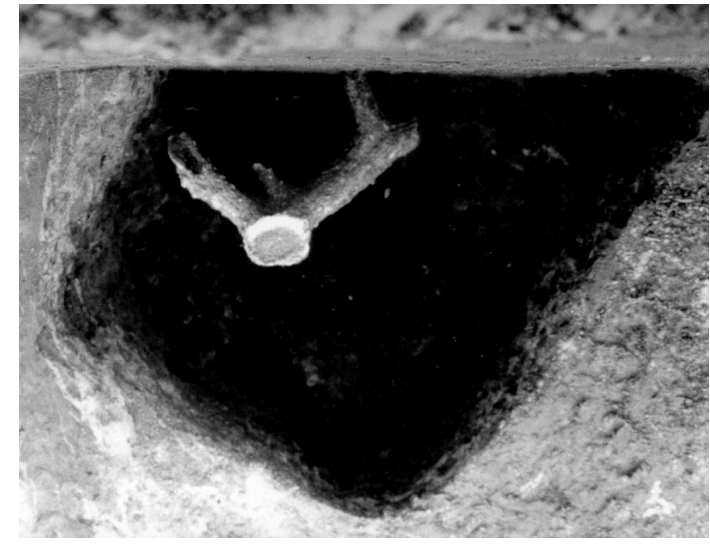

Fig. 8 - Le bois de cerf 1034/ 5 (photo C. Vallet, INRAP).

Les déplacements décrits ne permettent pas de déterminer précisément l'espace de décomposition. Leur nombre pourrait tout de même suggérer un comblement différé de l'espace sépulcral et donc un système de protection.

\section{MOBILIER ET DATATION}

Cette fosse a livré un bois de cerf, probablement associé au défunt (fig. 8). Il s'agit d'une partie de bois de chute, qui se compose d'une portion de la perche ( $L$ : env. $35 \mathrm{~cm}$ ) avec 3 andouillers, dont l'andouiller d'œil. Au niveau de la meule, il présente un raclage du cercle de pierrures sur un côté, dont la fraîcheur est sans équivoque sur son origine récente, relative à sa découverte. Aucune autre trace, sciage ou polissage, n'a pu être mise en évidence.

La datation obtenue sur os humain (Gra-16249 - Ly1157: $5440 \pm 80 \mathrm{BP}$, soit 4451 à 4045 av. J.-C., avec un maximum de probabilité entre 4403 et 4216 av. J.-C. $[67,1 \%]$ ) se place vers le troisième quart du Ve millénaire.

\section{LA FO SSE ET LA SÉPULTURE 3067}

\section{Morphologie et Comblement de LA Structure}

La fosse présentait un plan oblong d'environ $0,85 \mathrm{~m}$ sur 1,2 $\mathrm{m}$ et une profondeur conservée de $0,9 \mathrm{~m}$ (fig. 9). Les parois étaient légèrement évasées, le remplissage assez homogène. La sépulture (US 1) se situait au sommet du remplissage supérieur (US 2). Le sédiment argilosableux sous-jacent (US 3) était de même composition jusqu'à la base, mais une plus grande densité d'escargots a permis d'individualiser une séquence dans le tiers inférieur (US 4). 
Enfin, le squelette d'un blaireau, un jeune adulte, a été trouvé au fond de la fosse (US 5; fig. 10). Les os étaient mal conservés, mais le squel ette était probablement complet. La
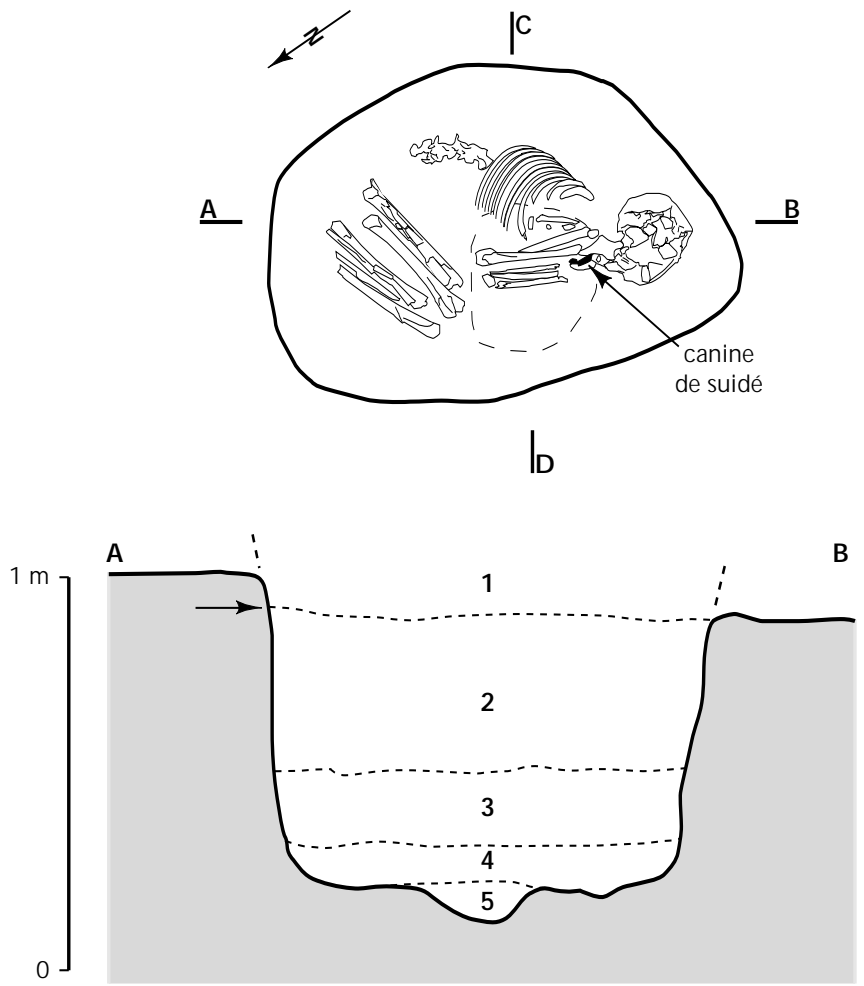

5 : blaireau

Fig. 9 - La fosse 3067 (dessin C. Vallet; infographie L. Loiselier, INRAP).

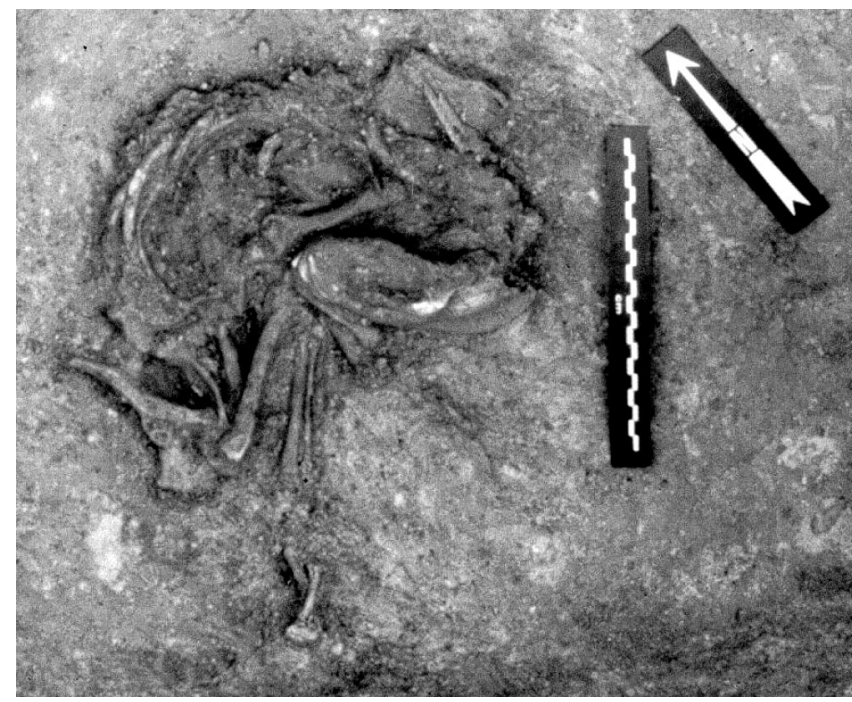

Fig. 10 - Squelette de blaireau 3067/5 (photo C. Vallet, INRAP). position est aisément lisible, l'animal reposait en position hyper-fléchie sur le côté gauche, dans un très léger surcreusement au centre. Aucune trace de découpe n'a pu être remarquée sur les ossements et les différentes carences sont probablement imputables à la taphonomie, car tous les secteurs anatomiques sont représentés, extrémités comprises. La présence de cet animal est peut-être fortuite. Cependant, la position centrale du surcreusement où il repose pourrait plaider en faveur de l'intentionnalité de son dépôt. Sa localisation ne permet toutefois pas de l'associer à la sépulture.

\section{LA SÉPULTURE}

Cette fosse recelait les restes d'un enfant d'environ 7 ans. La conservation des os était mauvaise (fig. 11). Les épiphyses, corps vertébraux, coxaux et petits os des extrémités étaient manquants ou très abîmés. Le défunt reposait en décubitus latéral gauche, membres supérieurs et inférieurs hyper-fléchis, dans un axe sud-ouest - nord-est, tête au sud-ouest.

Les relations anatomiques étaient dans l'ensemble préservées et la restitution de la position ne pose pas de

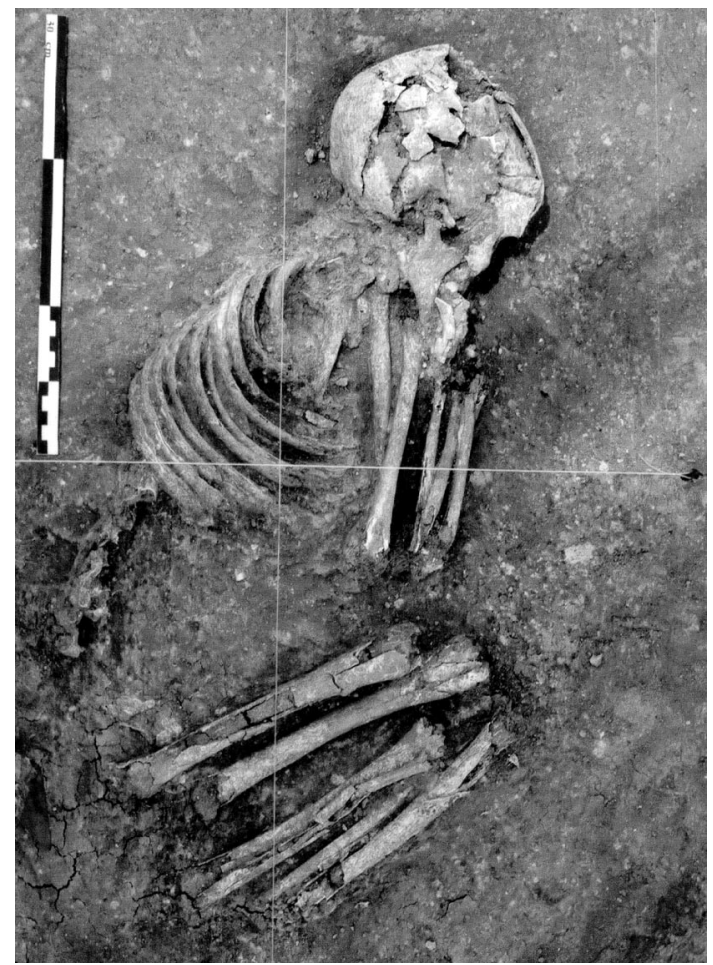

Fig. 11 - La sépulture 3067/ 1 (photo Y. Tchérémissin off, INRAP). 
problèmes. Cependant, des disjonctions notables étaient visibles au niveau des articulations de l'épaule droite, du genou droit et, plus faiblement, du genou gauche. En effet, l'épiphyse proximale de I'humérus droit, en vue postérieure, avait glissé à une dizaine de centimètres en direction de l'ouest. II se présentait ainsi parallèlement aux os de I'avant-bras. Les connexions formant l'articulation du coude se trouvaient également défaites. L'épiphyse distale du fémur droit était distante de plus de $5 \mathrm{~cm}$ de l'épiphyse proximale du tibia. La relation entre le tibia et la fibula était pourtant maintenue, bien que le tibia ait légèrement basculé en vue postéro-latérale. La liaison articulaire du genou gauche était aussi un peu défaite. Ces déplacements, qui concernent donc de grands os longs et qui s'effectuent pour certains hors du volume corporel (humérus droit, tibia droit et gauche), suggèrent que le sédiment n'exerçait pas une pression directe sur le corps lors de sa décomposition. Ces observations ne permettent pas cependant de préciser la nature du système de protection.

\section{MOBiLIER ET DATATION}

Un fragment de canine inférieure de suidé refendue et polie a été trouvé partiellement en appui sur la branche droite de la mandibule du défunt. Cet objet, prêté pour une exposition, a été égaré; on ne peut donc savoir s'il s'agissait d'un fragment d'outil de type racloir, tels que ceux trouvés dansle Néolithique ancien de l'abri J ean-Cros, Labastide-enVal, Aude (Camps-Fabrer, 1979) ou dans le Chasséen de Saint-Michel-du-Touch (Méroc, Simonnet, 1981) ou d'une pendeloque d'un type courant dans les contextes funéraires chasséens.

La datation (Gra-16247 - Ly-1158: $5470 \pm 60 \mathrm{BP}$, soit 4455 à 4054 av. J.-C., avec une probabilité maximale entre 4455 et 4221 av. J.-C. [94,6 \%]) se place dans le troisième quart du Ve millénaire.

\section{LA FO SSE ET LA SÉPULTURE 4000}

\section{Morphologie et comblement de LA Structure}

La fosse présentait un plan subrectangulaire de $0,7 \mathrm{~m}$ sur $1,4 \mathrm{~m}$ et une profondeur conservée d'environ 1,6 m (fig. 12). Les parois étaient légèrement évasées et un petit rétrécissement s'observait à la base. Le comblement argileux était assez homogène, mais le quart inférieur recelait les os de petits fouisseurs, de batraciens et de nombreux escargots (US 3). Les individus (US 2) reposaient dans le tiers
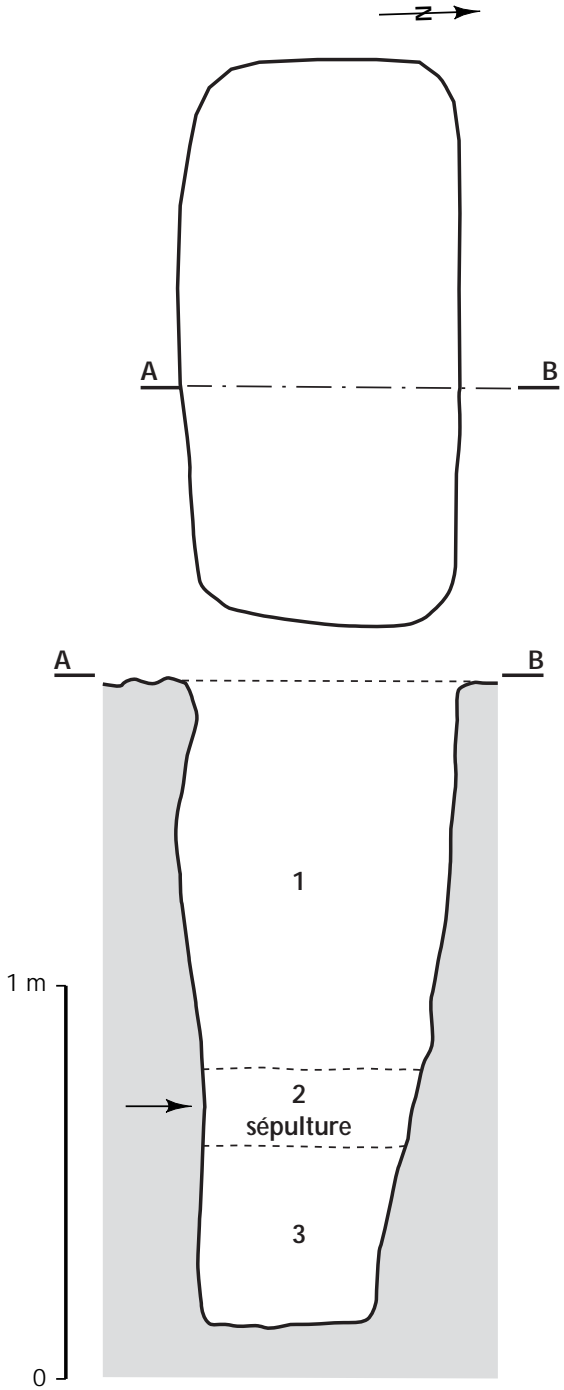

Fig. 12 - La fosse 4000 (dessin C. Vallet; infographie L L oiselier, INRAP).

inférieur du remplissage, sur un « lit » de charbons de bois localisé à l'est, sous leurs membres inférieurs. Ce «lit », qui définit la limite entre les US 2 et 3, était formé par des brandons de petites sections, dont les orientations étaient assez aléatoires ${ }^{3}$. Le comblement surmontant la sépulture (US 1) était très homogène et dépourvu de vestiges.

3. II s'agit de chêne caducifolié, selon P. Poirier (UMR 5059 du CNRS) qui a eu la gentillesse d'effectuer cette détermination. 


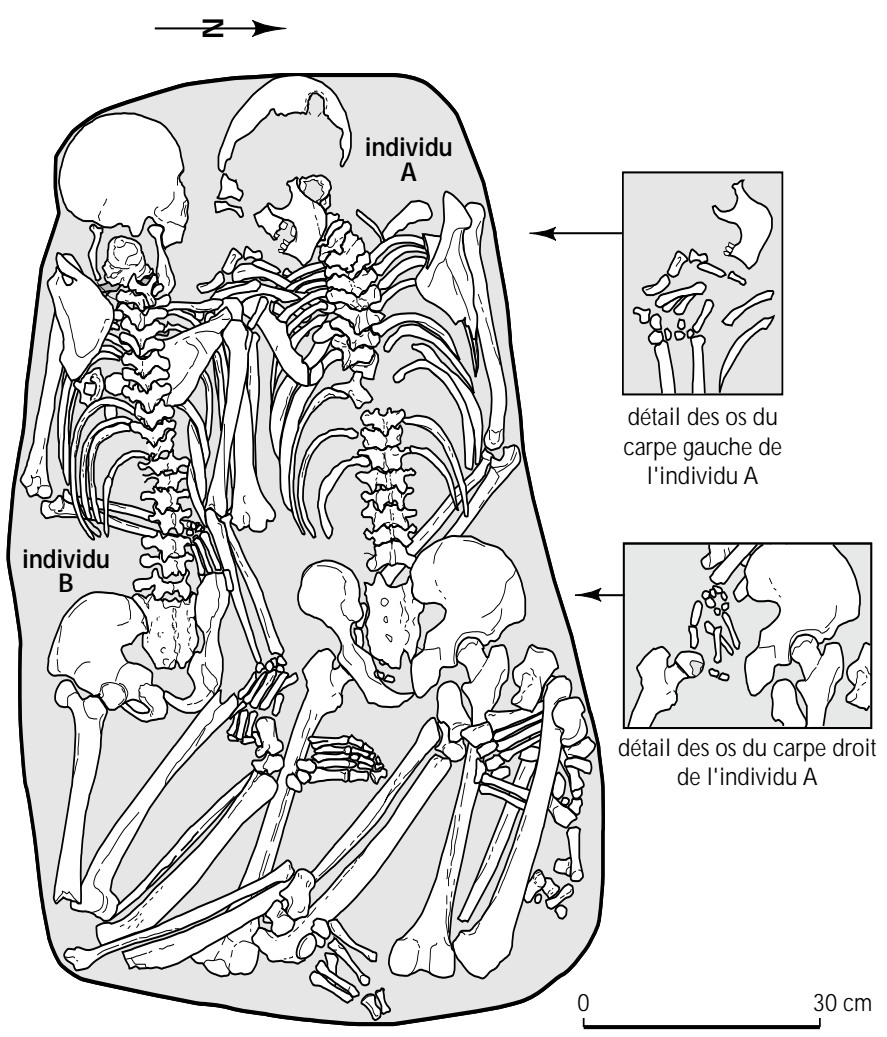

Fig. 13 - L a sépulture 4000 (dessin Y. Tchérémissin off; infographie L. L oiselier, INRAP).

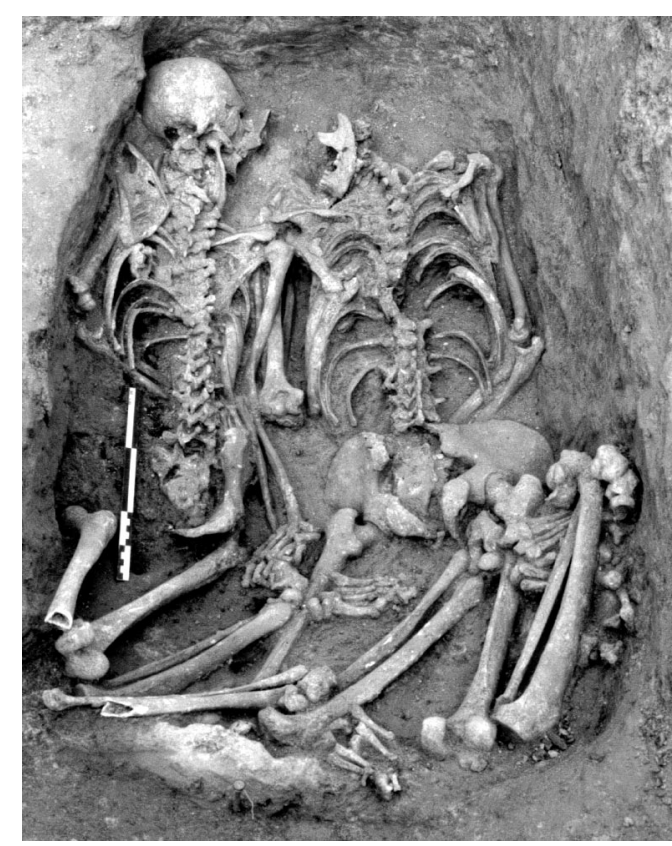

Fig. 14 - La sépulture 4000 en cours de démontage (photo Y. Tchérémissinoff, INRAP).

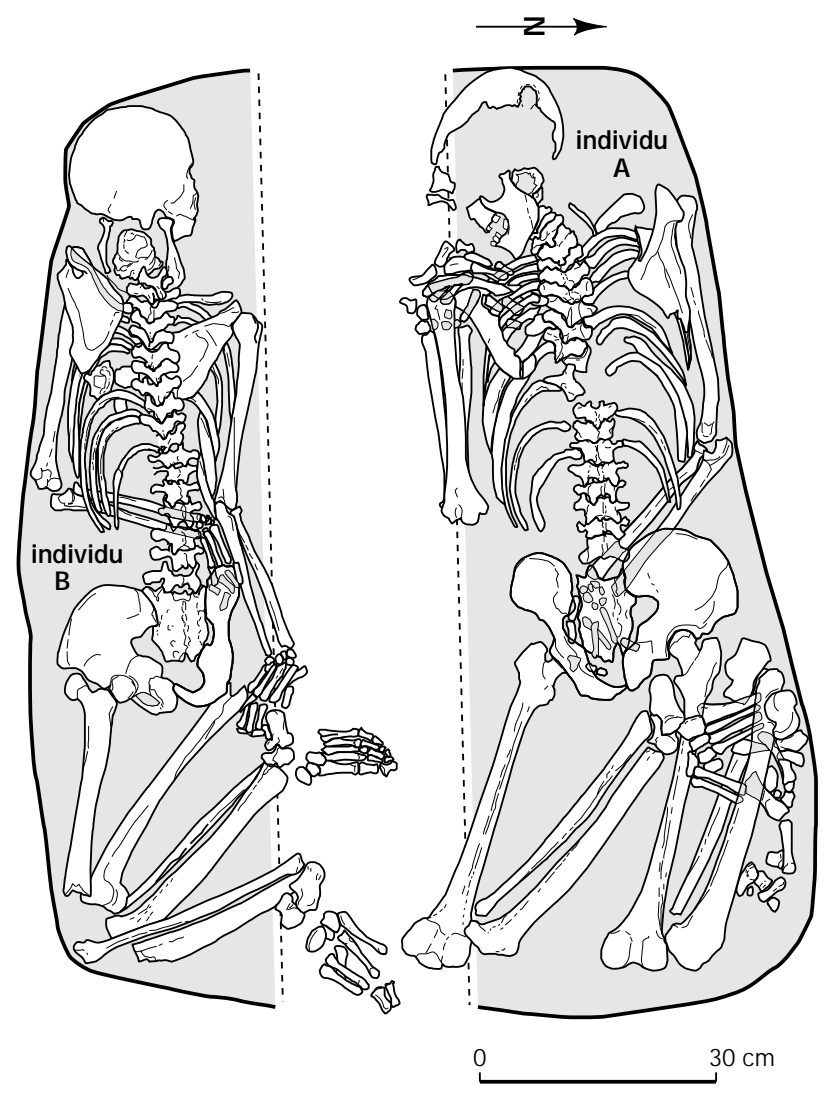

Fig. 15 - Présentation éclatée des individus A et $B$ (dessin Y. Tchérémissinoff; infographie L. L oiselier, INRAP).

\section{LA SÉPULTURE}

La sépulture 4000 contenait les restes de deux adultes, déterminés comme un homme (individu $A$, au nord) et une femme (individu $B$, au sud). Les os étaient très bien conservés et seules de petites ramifications imputables aux radicelles altéraient leurs surfaces corticales.

Les défunts étaient disposés dans un axe ouest-est, têtes à l'ouest. Ils reposaient sur le ventre, membres inférieurs fléchis ( fig. 13, 14 et 15). L'individu masculin présentait une semi-flexion du membre supérieur droit et une hyperflexion du membre supérieur gauche, l'individu féminin une extension du membre supérieur droit et une flexion du membre supérieur gauche.

Si la cohérence des relations anatomiques autorise une lecture aisée, les informations taphonomiques sont cependant complexes. À propos de la nature de l'espace de décomposition, nous constatons, tout d'abord, que les déplacements sont nombreux et concernent souvent des grands os longs. C'est le cas des membres inférieurs qui ont 


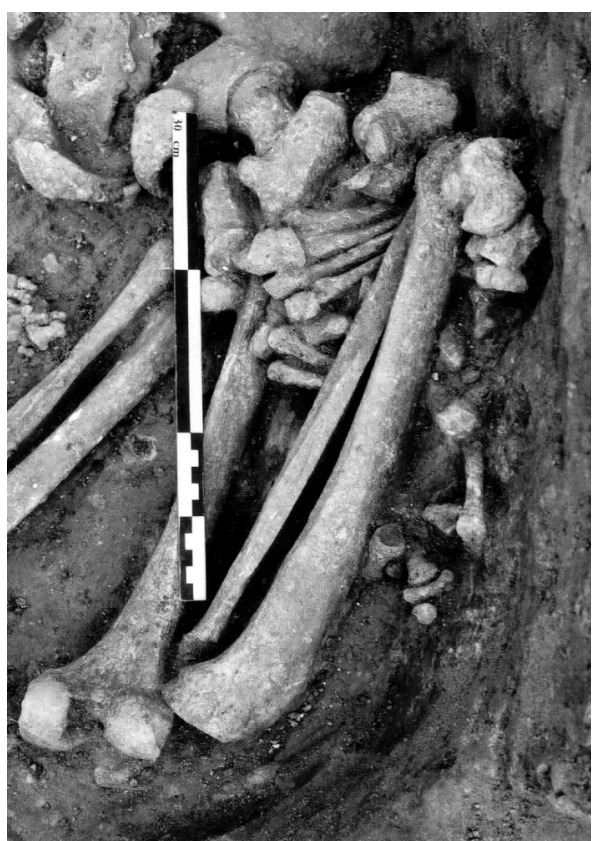

$4000 / 9$

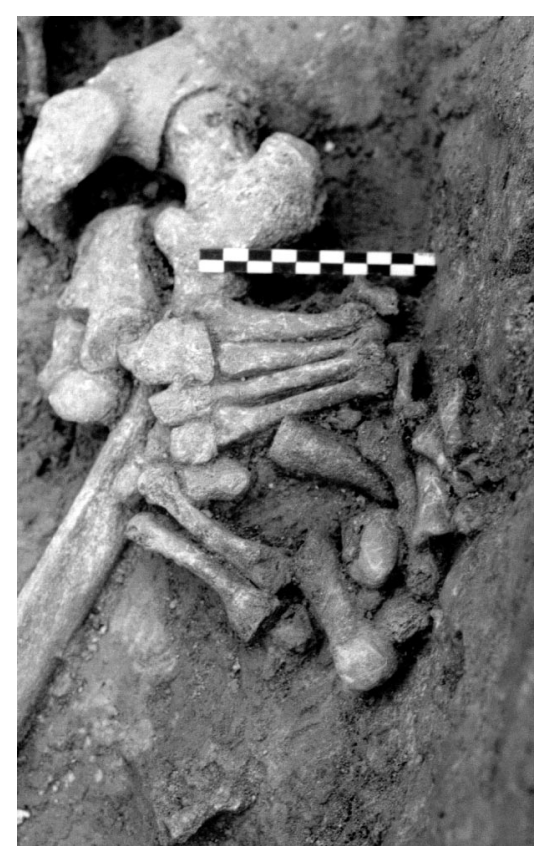

$4000 / 10$

Fig. 16 - Déail des pieds de l'in dividu A (photo Y. Tchérémissin off, INRAP).

effectué des mouvements de grande amplitude. Sur le membre inférieur gauche de l'individu B, par exemple, l'effondrement qui a suivi la dislocation des contentions de I'articulation du genou a entraîné une rotation complète du fémur, dont la tête est totalement déboîtée de l'acétabulum. Ces contentions semblent avoir cédé antérieurement à la dislocation des chevilles et de la plupart des éléments des pieds. En effet, l'éparpillement observé sur les os du pied droit de l'individu A, qui se distribuent pour certains sous le tibia, est ici probablement imputable à un appui temporaire de ce segment en élévation contre la paroi (talus reposant à plus de $10 \mathrm{~cm}$ au-dessus du calcanéus) (fig. 16). Les autres déplacements notables ont été observés sur les éléments du pelvis de l'individu $B$, qui a effectué un léger glissement en direction de l'axe médian; sur les côtes et certaines vertèbres, effondrées et disloquées à l'intérieur du volume thoracique, et sur les deux crânes, dont les positions des cervicales hautes (en vue supérieure), indiquent qu'ils étaient initialement maintenus en appui contre la paroi et aussi sur la mandibule de l'individu B. Cette dernière s'est visiblement effondrée avant le mouvement du crâne qui a exercé une pression sur les branches montantes exagérant I'ouverture de cette pièce.

L'ensemble des déplacements décrits plaide manifestement en faveur d'une décomposition en espace confiné, mais l'analyse relative à la dynamique de comblement se révèle un peu plus complexe. En effet, l'effondrement du volume thoracique, ainsi que l'absence de sédiment entre les os des membres inférieurs, témoignent incontestablement en faveur d'un comblement différé du volume corporel. Néanmoins, à l'image du maintien en élévation de certains éléments du tarse droit de l'individu A (fig. 16), plusieurs observations plaident en faveur d'infiltrations sédimentaires progressives partielles. C'est le cas du maintien de I'arc anatomique des différents carpes, du volume de flexion des phalanges de la main droite de l'individu $B$ et surtout du volume de la main gauche de l'individu A, dont les pièces épousent véritablement l'épiphyse proximale de I'humérus ( fig. 17). II n'est pas impossible que seule l'action des jus de décomposition sur le sédiment ait joué un rôle dans ces anomalies; mais elle ne peut expliquer leur ampleur et renvoie plutôt à l'existence d'un système de protection, rigide ou semi-rigide, quelque peu perméable.

Par ailleurs, nous avons remarqué des traces de coloration rouge sur les os du pied droit de l'individu $A$ et sur le tibia droit de l'individu B. Elles s'observaient également dans le sédiment contigu, de façon localisée. II s'agit probablement de nodules d'argile rubéfiés, peut-être en relation avec les charbons de bois trouvés à proximité.

La restitution des positions initiales des individus ne 


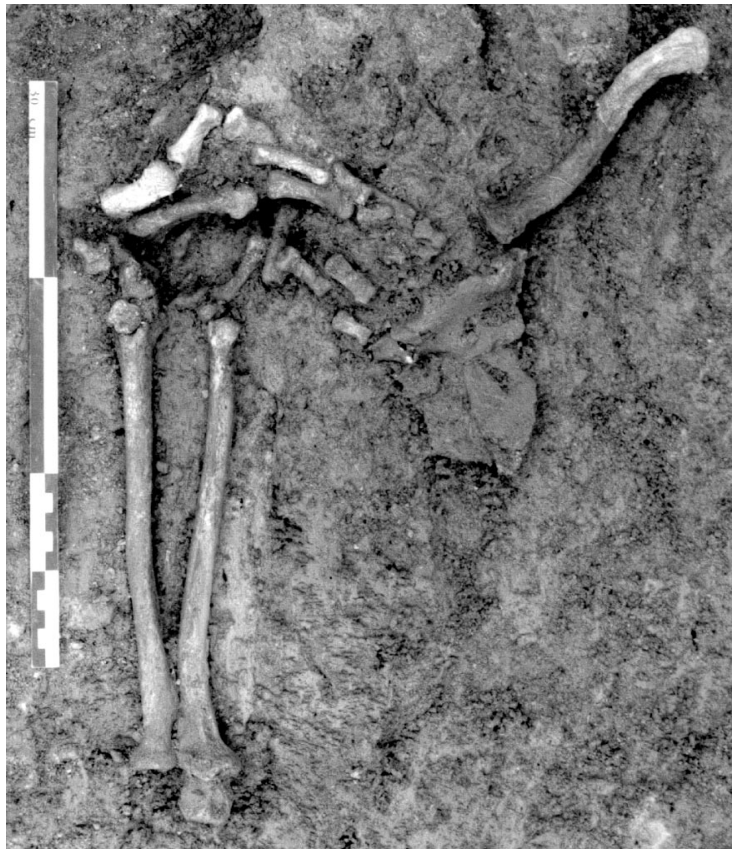

Fig. 17 - Détail des os du carpe gauche del'individu A (photo Y. Tchermissinoff, INRAP).

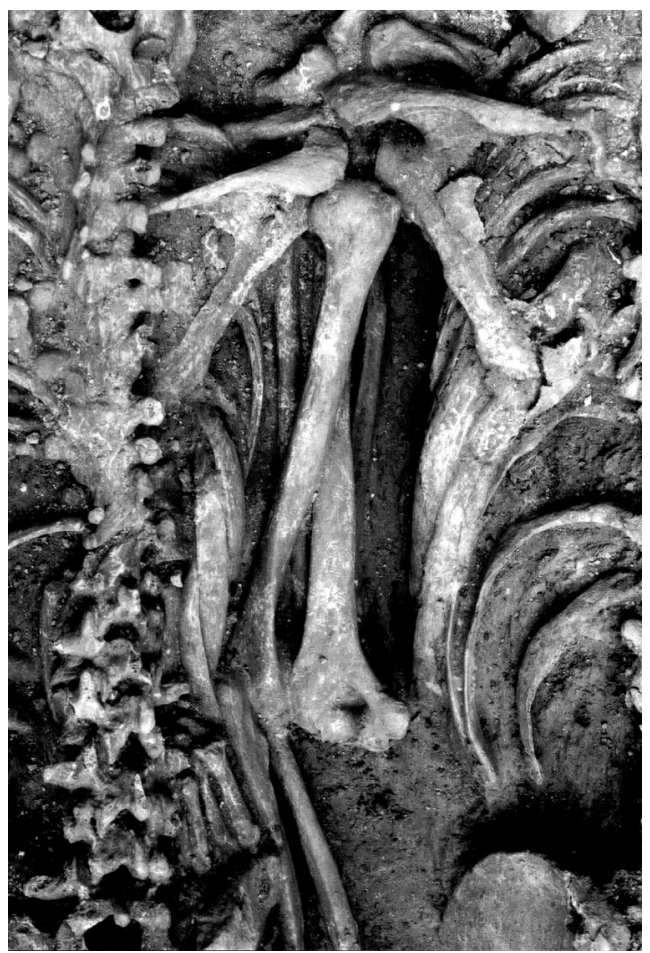

Fig. 18 - Détail des membres supérieurs contigus des individus A et B (photo Y. Tchérémissinoff, INRAP). pose pas vraiment de problème. II convient essentiellement de redresser les jambes en ramenant virtuellement les pieds en arrière des volumes fessiers et de relever un peu les crânes en appui contre la paroi. À ce propos, les nombreuses connexions préservées au niveau des pieds excluent, à notre avis, la présence d'un moyen de contention ayant initialement maintenu la flexion des membres inférieurs.

L'homme a indiscutablement été placé le premier, mais le caractère simultané des dépôts ne fait pas de doute. L'absence de sédiment entre les os se chevauchant peut être mentionnée, mais un argument pertinent est fourni par la scapula gauche de l'individu $A$. Elle se trouve légèrement relevée au contact des éléments de l'épaule de la femme, ce qui indique qu'elle était bien présente lors de l'affaissement du volume thoracique de l'autre individu (fig. 18). De nombreuses contraintes latérales sont d'ailleurs aisément lisibles sur les os de la femme, qui occupe un espace moindre dans cette sépulture.

\section{DATATION}

Aucun mobilier n'a été trouvé dans cette fosse. Les os des individus A et $B$ ont été datés ( $L y-9668$ : $5310 \pm 40 B P$, soit 4248 à 3997 av. J.-C. avec un maximum de probabilité entre 4248 et 4038 av. J.-C. [ 95,2 \%] pour l'individu A, et Ly11373: $5470 \pm 50$ BP, soit 4449 à 4168 av. J.-C., avec un maximum de probabilité entre 4373 et 4223 av. J.-C. [ $88,8 \%$ ] pour l'individu B). Malgré le caractère simultané des dépôts, ces deux résultats ne sont absolument pas superposables, ils se placent dans la seconde moitié du Ve millénaire avec un chevauchement vers 4200 av. J.-C.

\section{LA FOSSE ET LA SÉPULTURE 1020}

\section{Morphologie et Comblement de LA Structure}

La fosse présentait un volume cylindrique, d'un diamètre d'environ $0,7 \mathrm{~m}$ et d'une profondeur conservée de $1,2 \mathrm{~m}$ (fig. 19). Les parois étaient verticales et comportaient de nombreuses petites irrégularités. L'US 2 contenait le défunt qui était plaqué contre la paroi sud, presque verticalement, et sa partie supérieure avait anciennement été écrêtée par les labours. Le comblement sous-jacent (US 3 et 4), se composait d'un sédiment semblable, mais plus organique. II contenait des tessons et des restes fauniques. La plus grande densité de mobilier dans I'US 3 a autorisé la distinction de cette séquence, par ailleurs assez riche en 


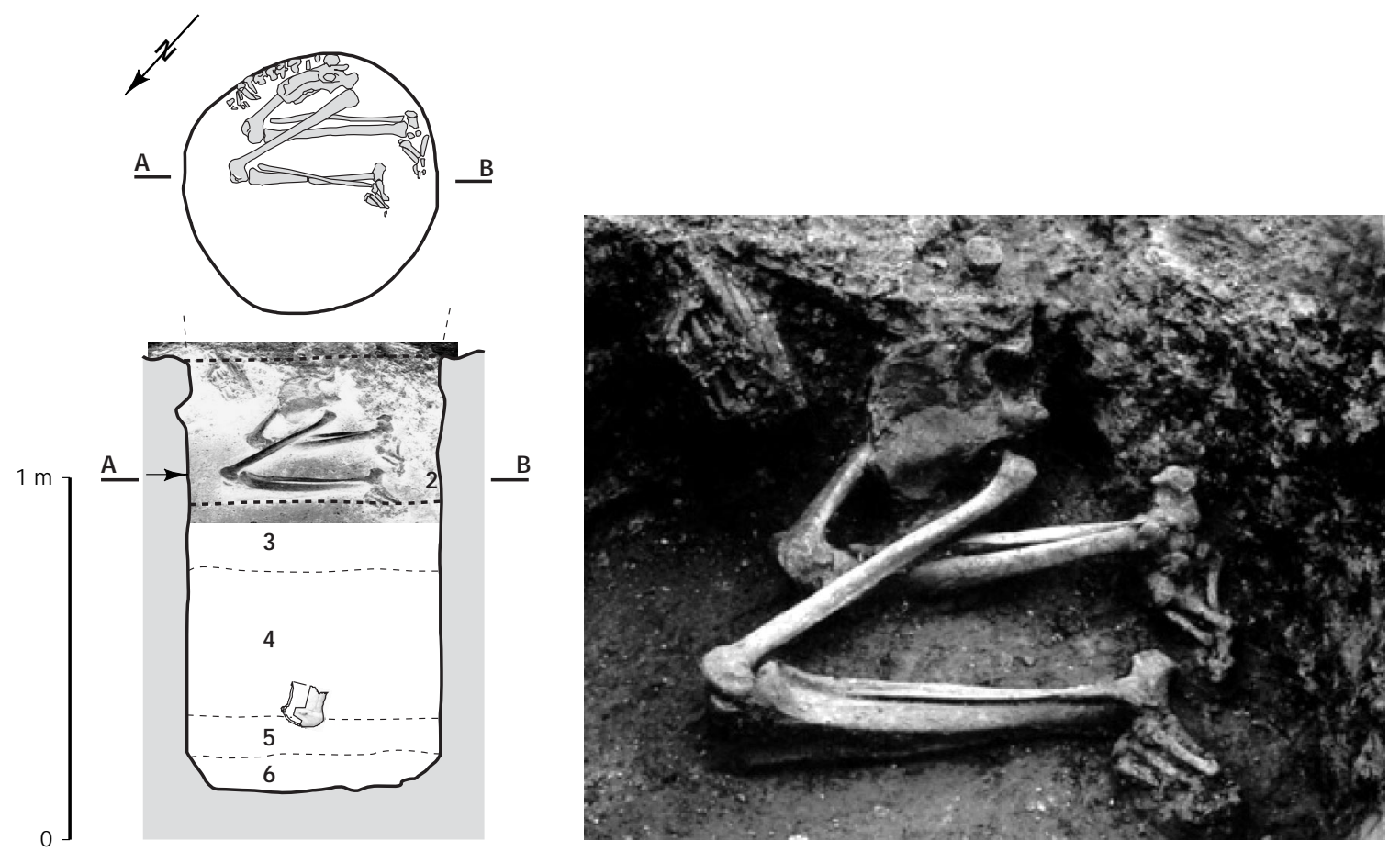

Fig. 19 - La fosse et la sépulture 1020 (dessin C. Vallet; infographie L. Loiselier; photo B. Boisseau, INRAP).

escargots. À 0,2 $\mathrm{m}$ du fond, à environ $0,5 \mathrm{~m}$ au-dessous du défunt, un vase dont le col était un peu abîmé (cassé et/ ou érodé), reposait en position subverticale au centre et au sommet d'un niveau très charbonneux d'environ $0,1 \mathrm{~m}$ d'épaisseur (US 5). II recelait également de nombreux tessons et restes fauniques, dont certains étaient altérés par des coups de feu. Une fine pellicule charbonneuse séparait cet ensemble du premier comblement (US 6), composé d'un « lit » de gravier, probablement issu de la dégradation des parois. Le fond de l'excavation, horizontal, était légèrement rubéfié, ainsi que la paroi nord sur son tiers inférieur.

La légère rubéfaction du fond et celle, plus marquée, de la paroi indiquent qu'une combustion a eu lieu au sein même de la fosse. Les traces de chauffe visibles sur certains os sont toutefois trop ponctuelles pour pouvoir affirmer qu'elles se sont produites sur place. Cependant, il ne faut sans doute pas envisager un laps de temps important entre le feu, le rejet des restes de faune et du vase. Tous ces éléments pourraient constituer un dépôt particulier, mais sa localisation ne permet pas d'étayer l'association à la sépulture. Les remplissages intercalaires sont de texture homogène et, même s'ils comportent de nombreux éléments, leur mise en place s'est effectuée dans un temps relativement court, comme le suggère la répartition verticale des tessons d'un même vase à barrettes biforées qui se trouvaient au contact des US 4-5 et dansI'US 3 à un mètre au-dessus.

\section{LA SÉPULTURE}

La sépulture 1020 contenait les restes d'un adulte dont le sexe n'a pas pu être déterminé. La portion supérieure du squelette, que l'érosion a fini par faire affleurer, a été anciennement arasée par les labours (fig. 19). Ne demeuraient, en assez bon état de conservation, que les trois dernières vertèbres thoraciques, le rachis lombaire, trois côtes, les éléments de la main droite, le coxal gauche, le sacrum et les deux membres inférieurs complets. L'individu reposait en position fléchie, dans un axe globalement nordest - sud-ouest, avec la partie supérieure du corps en appui subvertical contre la paroi méridionale.

La grande majorité des os se trouvaient en situation d'instabilité lors du dégagement. Ainsi, le carpe droit, les vertèbres et le coxal se situaient à plus d'une trentaine de centimètres de hauteur de la base du dépôt. Or, les déplacements sont peu nombreux, se limitant au seul volume corporel. Cette constatation ne peut s'expliquer que par la mise en place d'un comblement concomitant au 
dépôt de l'individu. Le maintien des éléments de la main suggère, de plus, que le sédiment était directement au contact du corps. Sur la position initiale, quelques précisions peuvent être apportées pour les os manquants. Tout d'abord, la situation de la main ne laisse aucun doute sur la flexion du membre supérieur droit. La position du sacrum, de la tête fémorale ainsi que la proximité de la paroi, indiquent que le coxal droit reposait en vue très latérale. Cette pièce s'est trouvée redressée sous l'effet d'une grande contrainte, qui est aussi observable sur la portion supérieure du tronc. En effet, la position très latérale droite du rachis, démontre qu'une très grande pression s'exerçait sur l'épaule gauche. II est probable que cette articulation jouxtait la paroi, ainsi que le crâne, qui devait être appuyé sur sa face latérale gauche. Les éléments supérieurs du squelette présentaient donc une rotation axiale totalement opposée à celle des membres inférieurs.

\section{Datation absolue}

La datation obtenue à partir des os humains (Ly-9669: $4705 \pm 50$ BP, soit 3633 à 3369 av. J.-C., avec une probabilité maximale entre 3475 et 3369 av. J.-C. [49,2 \%]) se place au milieu du IVe millénaire, elle est manifestement beaucoup plus récente que les autres.

\section{Mobilier céramique}

II s'agit essentiellement de céramique modelée à pâte sableuse dont l'inventaire par US suit.

\section{US 6}

Deux tessons fins et un tesson épais.

\section{US 5}

Vases restituables

1. Vase à col haut et panse cordiforme, dont le col est légèrement évasé et dont le raccord col-panse est souligné par une cannelure fine. Ce récipient mesure $10,5 \mathrm{~cm}$ de diamètre à l'embouchure pour $11,5 \mathrm{~cm}$ de haut, le col a une hauteur de $6,5 \mathrm{~cm}$ et le diamètre maximal de la panse est de $11,6 \mathrm{~cm}$. La suspension est assurée par un mamelon ovalaire à perforation horizontale, située sur le renflement de la panse. La pâte est à cœur rouge et surface noire bien polie, légèrement micacée et à dégraissant de sable quartzeux (fig. 20, n 7). Le col de ce vase était un peu abîmé.

2. Bord de coupe en calotte, d'un diamètre d'environ
$12 \mathrm{~cm}$ et d'une hauteur de $5,2 \mathrm{~cm}$, avec lèvre ronde et bord épaissi. II pourrait éventuellement s'agir du cuilleron d'une louche, vu le faible diamètre et le fort épaississement du bord, mais cette particularité peut aussi résulter d'un montage par estampage sur une matrice convexe, comme par exemple le fond rond d'un autre vase ou une vannerie (fig. 20, n० 8).

3. Bord de très grande coupe subtronconique, d'un diamètre d'environ $30 \mathrm{~cm}$ et d'une hauteur de $8,5 \mathrm{~cm}$, à fond très fin (épaisseur: $2,5 \mathrm{~mm}$ ) ce qui indique un montage par estampage (fig. 20, n 9). La pâte est grise, légèrement micacée à dégraissant de sable quartzeux à grains roulés. Un raccord existe avec un des tessons fins trouvés dans I'US 6.

Élément fragmentaire individualisable

Un bord rentrant de gros vase globuleux, probablement ovoïde qui porte un bouton ovalaire perforé horizontalement et placé sous le bord (fig. 20, nº 5).

Élément isolé

Préhension isolée. Un tesson de l'US 5 raccorde avec un tesson de l'US 4 pour former une même barrette au moins biforée qui devait se trouver sur le renflement d'une panse convexe. L'aspect frais des cassures suggère que cet élément devait se trouver au contact des deux unités stratigraphiques.

Éléments atypiques

10 tessons fins et 11 tessons épais.

\section{US 4}

Éléments fragmentaires in dividualisables

1 petit bord rentrant concave à lèvre ourlée extérieurement;

5 fragments d'une panse convexe de probable vase à col présentent les traces d'au moins deux barrettes, dont une entière biforée. La teinte orangée de la face interne suggère qu'ils proviennent du même vase.

Éléments atypiques

7 tessons fins ( dont un de panse très convexe: vase à col probable) et 16 tessons épais.

\section{US 3}

Vase restituable

Un fragment de coupelle en calotte, à bord relevé très convexe présentant un diamètre d'environ $12 \mathrm{~cm}$, dont la préhension est assurée par un mamelon prismatique étroit perforé horizontalement (fig. 20, nº 4). La pâte est orangée légèrement micacée, à dégraissant de sable quartzeux à 

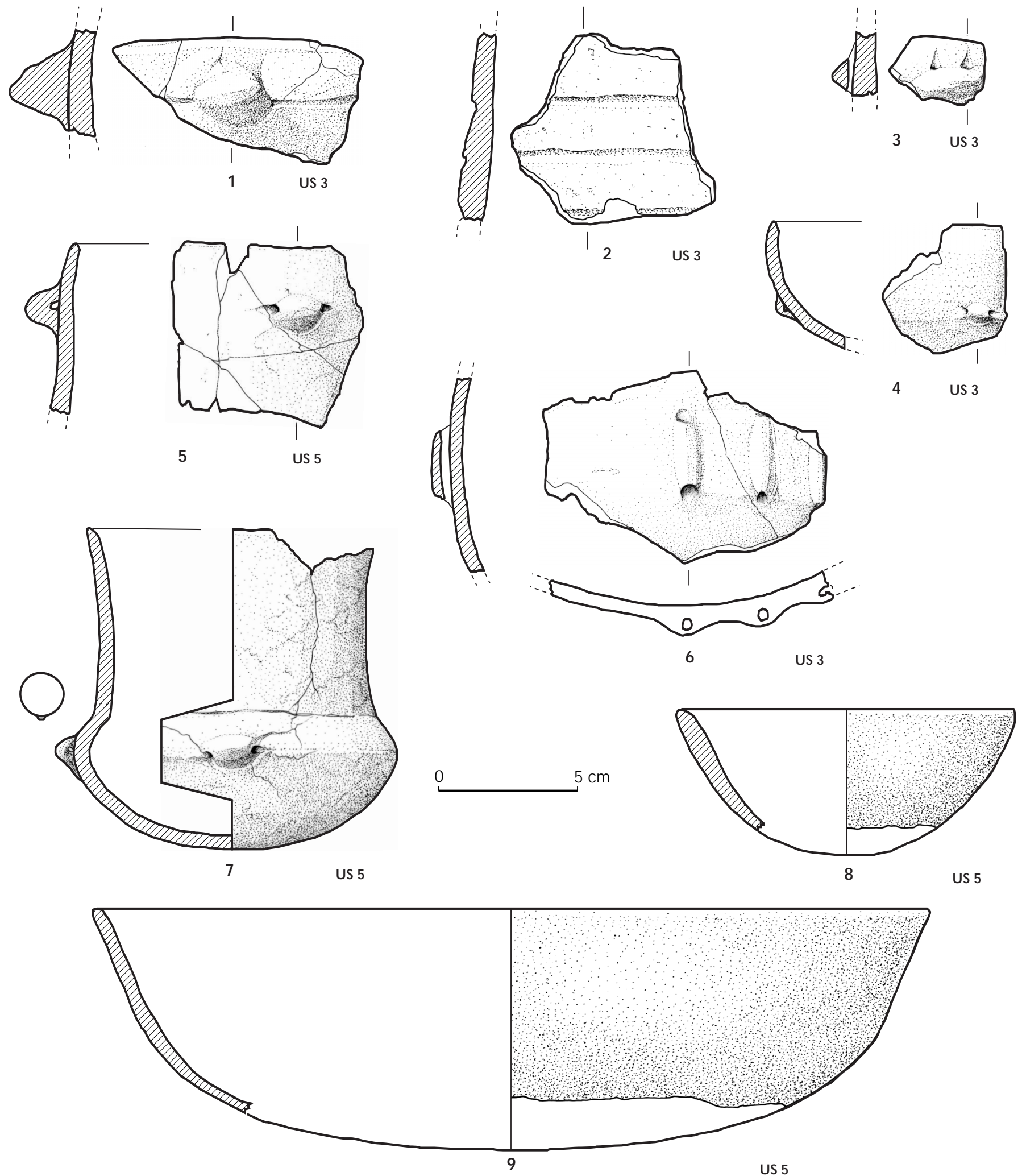

Fig. 20 - 1-9 : la céramique 1020/3 et 1020/5 (dessin Y. Tchérémissin off et J. Vaquer; infographie L. Loiselier, INRAP). 
grains roulés.

Éléments fragmentaires in dividualisables

1 bord rentrant concave de vase globuleux;

1 tesson convexe avec barrette biforée (sans doute du même vase que ceux des US 4 et 5 en raison de l'aspect orangé de la face interne) ;

1 fragment de panse à peu près sphérique, portant des tubulures perforées verticalement qui devaient former un système de suspension comportant au moins trois éléments groupés (fig. 20, $n^{\circ} 6$ ) ;

1 fragment avec trace d'un élément de préhension perforé verticalement et arraché;

2 tessons d'un gros vase probablement globuleux, dont un porte une languette et un décor de cannelures horizontales qui semblent correspondre aux lignes de jonction des colombins. L'autre tesson appartenant au même vase montre la trace d'au moins trois cannelures horizontales identiques (fig. 20, nos 1,2 ).

Éléments atypiques

5 tessons fins, 26 tessons épais et un fragment de torchis.

\section{LES RESTES DE FAUNE}

Des restes fauniques ont été recueillis dans les US 3, 4 et 5 , sous-jacentes au squelette humain.

\section{US 3}

Plusieurs espèces animales ont été reconnues dans ce niveau.

Ce sont les Bovinés qui sont les mieux représentés avec 5 restes qui se répartissent de la manière suivante: une portion d'hémi-mandibule, un talus droit, une première phalange et deux métatarses, un droit et un gauche. Ces deux dernières pièces se rapportent à deux animaux différents dont I'un est un adulte et l'autre un juvénile âgé d'environ 24 mois. Tous deux concernent la forme Bos taurus L. Les vestiges consistent essentiellement en des restes de pattes. Des stries de découpe sont visibles sur les faces latérale et médiale d'une extrémité proximale de métatarse, ainsi que sur la face médiale d'un talus, et des traces de feu ont été observées sur la portion distale du deuxième métatarse identifié.

Quatre restes de suidés ont été déterminés. II n'est pas possible, au vu des pièces examinées, de préciser s'il s'agit du porc ou du sanglier, les deux formes pouvant être présentes. Toutefois I'observation des vestiges, un fragment de coxal, un métapode d'un doigt accessoire et une troisième phalange, qui sont de petite taille, nous incline à penser à une forme domestique plutôt que sauvage. Deux adultes sont issus de ce niveau. En effet, outre les pièces précédemment citées, une portion distale de radius gauche de forte taille a été identifiée, qui semble témoigner de la présence d'un mâle. On relève des traces de feu sur son épiphyse. Les quelques restes attribués à ce taxon ne font pas apparaitre de représentation anatomique particulière.

Une portion distale d'humérus droit de cerf adulte a égal ement été déterminée.

\section{US 4}

Le Chien (Canis familiaris) est figuré par deux os de la patte postérieure, un fémur et un tibia gauches attribuables à un sujet adulte.

Les Suidés sont les plus nombreux dans ce niveau avec 9 restes qui se répartissent entre 3 animaux différents au minimum : un infantile âgé de moins de 3 mois représenté par un fragment de pariétal et une portion de scapula; un juvénile de moins de 1 an auquel se rapportent un humérus gauche dont les épiphyses ne sont pas soudées et une première phalange dont l'épiphyse proximale n'est pas soudée; un autre juvénile de moins de 2 ans représenté par une extrémité de patte postérieure (MTT II, III, IV). Pour ce dernier, les métatarsiens III et IV présentent, par endroits, une légère coloration sombre d'aspect brûlé. Un petit fragment de crâne et une portion de diaphyse de tibia, dont il n'est pas possible de préciser leur éventuelle attribution à tel ou tel individu précédemment identifié, ont également été déterminés. II est impossible, là encore, de dire si ces différents vestiges sont attribuables au porc ou au sanglier. Toutefois, la forte représentation des sujets immatures nous incline plutôt à penser qu'il s'agit d'une forme plutôt domestique que sauvage.

Les Bovinés sont représentés dans cette US par trois vestiges: deux grands sésamoïdes et une portion d'ischion gauche. Cette dernière pièce porte de légères traces sombres qui semblent davantage être le fait d'un contact avec une source de chaleur plutôt qu'une combustion directe.

\section{US 5}

Dans cette US, ce sont les restes de suidés qui sont les plus nombreux, ils sont représentés par 53 vestiges. L'analyse de ces pièces a permis de mettre en évidence la présence d'au moins 6 individus:

- un infantile âgé de moins de 3 mois: ce sont uniquement 
des fragments crâniens (occipital, pariétal, frontal) qui ont été retrouvés. II est probable qu'il s'agit du même individu que celui identifié dans I'US 4, sus-jacente;

- quatre juvéniles:

- un âgé de moins de 12 mois est représenté par une patte antérieure gauche ( 1 humérus et radius gauches) ;

- un autre âgé d'environ 24 mois a livré un coxal et un tibia droits;

- une patte antérieure gauche représentée par une scapula, un humérus, un radius et un ulna se rapportent à un troisième animal âgé de moins de 36 mois;

- la présence d'une autre patte antérieure gauche est révélée par un humérus, un radius et un ulna attribuables à un quatrième sujet âgé de moins de 42 mois;

- divers vestiges trahissent la présence d'un adulte au moins: c'est le cas d'une portion d'hémi-mandibule gauche portant une première molaire usée ainsi que d'un troisième et d'un quatrième métacarpien.

D'autres restes, qui consistent en portions de maxillaire, de mandibules, d'os longs, une portion distale de fibula non latéralisée et dont l'épiphyse n'est pas soudée, de métapodes ou encore de fragments de vertèbres et de côtes n'ont pu être attribués de façon fiable aux sujets précédemment identifiés. La taille des ossements n'apporte aucune précision sur le statut, domestique ou sauvage, des animaux, d'autant que la grande majorité d'entre eux s'avère être immature. On note une forte représentation des pattes antérieures gauches.

Onze restes sont attribuables aux Bovinés:

- 2 portions de deux vertèbres cervicales;

- 1 trochanter de fémur non soudé indiquant pour l'animal dont il est issu un âge de moins de 36 mois;

- 1 portion de patte postérieure droite représentée par un fragment distal de tibia avec talus et calcanéum droits rapportables à un sujet adulte;

- 1 portion proximale de tibia droit d'adulte;

- 1 portion distale de tibia droit d'adulte;

- 1 portion distale de tibia gauche d'adulte;

- 1 portion de diaphyse de tibia non latéralisée d'adulte.

Ces différents vestiges concernent un minimum de quatre spécimens, trois adultes et un juvénile de moins de 36 mois, représentés essentiellement par des portions de pattes postérieures. On ne relève aucun indice de sur- ou sous-représentation des parties droite ou gauche du squelette. Deux tibias présentent des traces sombres par endroits, qui semblent, encore une fois, être dues à un contact avec une source de chaleur plutôt qu'à une combustion directe.

Les Caprinés sont représentés par un humérus et un radio-ulnaire gauches ainsi que par un fémur droit. Ces trois pièces appartiennent vraisemblablement à un même animal âgé d'environ 2 ans.

Les vestiges identifiés dans la structure 1020 révèlent la présence de plusieurs animaux: 1 chien adulte, 6 suidés parmi lesquels on compte 1 infantile âgé de moins de 3 mois, 3 juvéniles et 1 jeune adulte, 1 cerf adulte, ainsi que 3 bovinés adultes et 1 juvénile.

Le Chien est représenté par une patte postérieure gauche et des traces de découpe sont visibles sur le fémur.

Pour ce qui concerne les Suidés, on remarque que le sujet infantile, âgé de moins de 3 mois a livré uniquement des restes crâniens (un fragment de pariétal et un fragment d'occipital). Par ailleurs, pour la majorité des restes attribués à ce groupe, on ne peut que noter la forte proportion des restes de pattes antérieures gauches. Pour ce qui est des Bovinés, les pièces déterminées consistent essentiellement en des portions de pattes postérieures. On ne note aucun indice de sur- ou sous-représentation des parties droite ou gauche du squelette.

Concernant les Caprinés, peu nombreux, ce sont aussi les restes de pattes qui les caractérisent.

De rares traces de découpe ont été observées sur certains ossements.

La nature des dépôts de faune et leur situation dans la fosse, à différents niveaux sous-jacents au défunt, ne peuvent permettre d'affirmer leur stricte association à la sépulture.

Certaines pièces montrent des traces sombres liées à une combustion indirecte (à mettre en relation avec la partie basse, charbonneuse?) II s'agit d'une portion distale de radius gauche et d'un tibia de suidé ainsi que d'une portion de coxal, de tibia, d'un talus et d'une portion distale de métatarse de boviné. Par ailleurs, deux métatarsiens de suidé montrent des traces de feu. L'aspect très localisé de ces traces suggère que ces restes n'ont pas été brûlés directement, mais ont plutôt été en contact avec une source de chaleur indirecte, telle qu'une sole de cuisson à pierres chauffées. Ces traces d'ustion et la présence de stries de découpe suggèrent que la plupart de ces restes représentent des rejets de consommation. 
Tabl. I - Estimation del'âge au décès des individus de $\mathrm{N}$ arbons, avec CFA M oorees (M oorees et al., 1963 a et b) et O wing-Webb (O wingWebb, Suchey, 1985) et du sexe des adultes, avec P. M urail (M urail et al., 1999) et J. Bruzek (Bruzek, 1992) : f, féminin ; m, masculin ; i, sexe in déterminé.

\begin{tabular}{|l|c|c|c|c|c|}
\hline Sujet/sexe & $4000 \mathrm{~B}(\mathrm{f})$ & $4000 \mathrm{~A}(\mathrm{~m})$ & $1020(\mathrm{i})$ & 1034 & 3067 \\
\hline Âge au décès & $\geq 30$ ans & $\geq 30$ ans & adulte & $0,5-1$ an & $7,5-9,5$ ans \\
\hline
\end{tabular}

\section{INFORMATIONS RELATIVES À LA PALÉOBIOLOGIE}

Cette étude a pour objectif de définir la composition du « groupe » de Narbons: sexe, âge, stature (tabl. I à VI). En outre, un examen paléopathologique s'imposait pour tenter d'éclairer I'histoire des individus $A$ et $B$ de la sépulture 4000 , ainsi que les circonstances de leur décès.

La conservation du matériel anthropologique est variable. Les restes osseux des individus immatures sont très fragmentaires. Parmi les adultes, le squelette de la sépulture 1020 est amputé par l'érosion dans sa partie supérieure. Les sujets de la sépulture double ont une bonne conservation générale des os à l'exception des blocs cranio-faciaux: les faces sont très fragmentées (sauf les maxillaires et les mandibules). Les pièces neurocrâniennes montrent des déformations, d'origine taphonomique. Toute reconstitution satisfaisante des boîtes crâniennes a dès lors été impossible (chevauchement des pièces osseuses).

\section{ÂGE AU DÉCÈS ET DIAGNOSE SEXUELLE}

La petite série de Narbons se compose de deux sujets immatures (sépultures 3067 et 1034), et de trois adultes (sépultures 1020 et 4000). L'individu 1020 appartient à la classe des adultes sans qu'il soit possible d'apporter plus de précision, en raison de l'absence des clavicules.

Pour les adultes, on trouve une femme (B 4000), un homme (A 4000), et un sujet de sexe indéterminé (1020). En ce qui concerne les sujets immatures, on ne dispose pas à I'heure actuelle de méthode permettant une estimation fiable du sexe car il n'existe pas de différence morphologique notable chez les individus dont la croissance n'est pas terminée (Majo et al. 1993).
Tabl. II - Caractères métriques des blocs crânio-faciaux (les codes alpha-n umériques correspondent aux variables utili sées dan s l'étu de mérique comparative).

\begin{tabular}{|c|c|c|}
\hline \multirow[t]{2}{*}{ Mesures en mm selon Martin in Bräuer (1988) } & \multicolumn{2}{|c|}{ Sujets } \\
\hline & Ind. B & Ind. A \\
\hline Longueur maximale (1) LM 1 & 184,0 & 198,0 \\
\hline Longueur glabelle-inion (2) LG12 & 151,0 & 170,0 \\
\hline Largeur transverse maximale (8) LTRM 8 & 147,5 & 150,0 \\
\hline Largeur biastérique (12) LAA12 & 110,0 & 116,0 \\
\hline Largeur biauriculaire (11) & 126,5 & \\
\hline Hauteur basio-bregmatique (17) & 122,0 & \\
\hline Hauteur porio-bregmatique (20) HPB20 & 107,3 & 119,9 \\
\hline Périmètre horizontal (23) PEH 23 & 522,0 & 459,0 \\
\hline Périmètre frontal (24) PEF24 & 312,0 & 341,0 \\
\hline Périmètre sagittal (25) & 381,0 & \\
\hline Arc frontal (26) ACF26 & 135,0 & 145,0 \\
\hline Corde frontale (29) COF29 & 112,0 & 124,0 \\
\hline Arc pariétal (27) ACP27 & 130,0 & 140,0 \\
\hline Corde pariétale (30) CO P30 & 116,0 & 119,0 \\
\hline Arc occipital (28) & 119,0 & \\
\hline Corde occipitale (31) & 100,0 & \\
\hline Longueur du foramen magnum (7) & 37,5 & \\
\hline Largeur du foramen magnum (16) & 28,0 & \\
\hline Longueur de la base (5) & 88,5 & \\
\hline Longueur du palais (62) & 45,0 & 42,0 \\
\hline Largeur du palais (63) & 33,0 & 35,2 \\
\hline Longueur maxillo-alvéolaire (60) & 54,0 & \\
\hline Largeur maxillo-alvéolaire (61) & 61,0 & \\
\hline Capacité cranienne (M anouvrier, 38c), Homme & 1452,2 & \\
\hline Capacité cranienne (M anouvrier, 38c), Femme & 1532,9 & \\
\hline Capacité cranienne (Lee et Pearson, 38d au basion), Homme CC38D & 1405,3 & \\
\hline Capacité cranienne (Lee et Pearson, 38d au basion), Femme & 1328,5 & \\
\hline Capacité cranienne (Lee et Pearson, 38d au porion), Homme & 1422,7 & 1659,3 \\
\hline Capacité cranienne (Lee et Pearson, 38d au porion), Femme & 1388,9 & 1632,0 \\
\hline Indice cranien horizontal $(11,8 / 1)$ & 80,2 & 75,8 \\
\hline Indice de hauteur-Iongueur au basion $(12,17 / 1)$ & 66,3 & \\
\hline Indice de hauteur-Iongueur au porion $(14,20 / 1)$ & 58,3 & 60,6 \\
\hline Indice de hauteur-largeur au basion $(13,17 / 8)$ & 82,7 & \\
\hline Indice de hauteur-largeur au porion $(15,20 / 8)$ & 72,8 & 79,9 \\
\hline Indice mixte de hauteur au basion $((17 / 1+8) * 2)$ & 73,6 & \\
\hline Indice mixte de hauteur au porion $((20 / 1+8) * 2)$ & 64,8 & 68,9 \\
\hline Indice du foramen magnum $(133,16 / 7)$ & 74,7 & \\
\hline Indice palatin $(158,63 / 62)$ & 73,3 & 83,7 \\
\hline Indice maxillo-alvéolaire $(154,61 / 60)$ & 113,0 & \\
\hline Indice frontal sagittal $(122,29 / 26)$ & 83,0 & 85,5 \\
\hline Indice pariétal sagittal $(124,30 / 27)$ & 89,2 & 85,0 \\
\hline Indice occipital sagittal $(125,31 / 28)$ & 84,0 & \\
\hline Largeur bigoniaque mandibule (66) & & 90,0 \\
\hline
\end{tabular}


Tabl. III - Classification de la capacité crânienne des adultes de Narbons ( $A$ et $B$ ) d'après la méthode de M anouvrier (1880) \& Le Pearson (in Braüer, 1988).

\begin{tabular}{|c|c|l|l|l|}
\hline Individus & Sexe & $\begin{array}{l}\text { Capacité crânienne } \\
\text { (porion) } \\
\text { Lee-Pearson (1901) }\end{array}$ & $\begin{array}{l}\text { Capacité crânienne } \\
\text { (basion) } \\
\text { Lee-Pearson (1901) }\end{array}$ & $\begin{array}{l}\text { Capacité crânienne } \\
\text { (basion) } \\
\text { Manouvrier (1880) }\end{array}$ \\
\hline B & F & $\begin{array}{l}\mathbf{1 3 8 8 , 9} \\
\text { aristencéphale) }\end{array}$ & $\begin{array}{l}\mathbf{1 3 2 8 , 5} \\
\text { (aristencéphale) }\end{array}$ & $\begin{array}{l}\mathbf{1 5 3 2 , 9} \\
\text { (aristencéphale) }\end{array}$ \\
\hline A & M & $\begin{array}{l}\mathbf{1 6 5 9 , 3} \\
\text { (aristencéphale) }\end{array}$ & & \\
\hline
\end{tabular}

\section{DIMORPHISME SEXUEL DES SUJETS A ET B}

L'analyse morphométrique fait apparaître un dimorphisme sexuel net entre les deux individus de la sépulture 4000. Cette différence de format entre les sexes est courante en anthropologie. En revanche le caractère pédomorphe généralement accordé par les travaux antérieurs (Riquet, 1970), aux individus masculins chasséens, ne se manifeste pasici.

L'individu masculin A peut être classé parmi les individus robustes. Ce sujet montre des dimensions postcrâniennes et crâniennes importantes, avec de fortes valeurs pour les périmètres minimaux et les indices de robustesse. Les extrémités proximales et distal es sont massives, les insertions musculaires marquées. Inversement, les sujets $B$ et 1020 présentent des dimensions inférieures. Mais seul le sujet 1020, sans doute plus récent, peut être qualifié d'individu gracile. Cet aspect est renforcé par la massivité des extrémités relativement à la longueur et aux périmètres des os longs, ainsi que la faiblesse des insertions musculaires, alors que le sujet $B$ présente des os longs dont les diaphyses sont courtes mais relativement épaisses.

\section{APPARENTEMENT BIOLOGIQUE DES INDIVIDUS A ET B DE LA SÉPULTURE 4000}

Les caractères discrets sont des variations morphologiques dont le déterminisme est complexe ou mal connu, et leur héritabilité pas toujours très bien définie (Saunders, 1978; Crubézy, 1991a; Castex, 1994; Gemmerich Pfister, 1999). En raison de ces limites, nous présentons uniquement les caractères qui constituent des arguments possibles en faveur d'un apparentement biologique.

L'observation des voûtes crâniennes des individus $A$ et $B$ a révélé des dépressions (bilatérales chez le sujet $A$, et unilatérale chez le sujet $B$ ) situées sur le toit pariétal. L'examen tomodensitométrique ( fig. 21) confirme le diagnostic d'un amincissement dysplasique de la voûte crânienne; l'étio-
Tabl. IV - Caractères métriques des membres supérieurs (les codes alpha-numériques correspondent aux variables utilisées dans l'étude mériqu e comparative).

\begin{tabular}{|c|c|c|c|c|}
\hline \multirow{2}{*}{$\begin{array}{l}\text { O s et mesures en mm selon Martin } \\
\text { in Bräuer (1988) }\end{array}$} & \multicolumn{4}{|c|}{ Sujets } \\
\hline & Ind. B & Ind. B & Ind. A & Ind. A \\
\hline Clavicule & d & $\mathbf{g}$ & d & $\mathbf{g}$ \\
\hline Longueur maximale (1) & 132,5 & 131,5 & 144,0 & 147,5 \\
\hline Diamètre vertical au milieu (4) & 10,7 & 10,2 & 13,0 & 12,0 \\
\hline Diamètre sagittal au milieu (5) & 12,1 & 10,9 & 12,5 & 13,5 \\
\hline Périmètre au milieu (6) & 36,0 & 39,0 & 43,0 & 45,0 \\
\hline Indice de robustesse (6/1) & 27,2 & 29,7 & 29,9 & 30,5 \\
\hline Indice diaphysaire $(4 / 5)$ & 88,4 & 93,6 & 104,0 & 88,9 \\
\hline H umérus & d & g & d & g \\
\hline Longueur maximale (1) HUMM 1 & 275,0 & 266,8 & 313,0 & 310,0 \\
\hline Longueur totale (2) HUM M 2 & 271,0 & 266,0 & 311,0 & 308,0 \\
\hline Largeur de l'extrémité proximale (3) HUMM 3 & 43,0 & 41,0 & 52,0 & 50,0 \\
\hline Largeur de l'extrémité distale (4) HU M M 4 & 54,0 & 51,0 & 65,5 & 67,0 \\
\hline Diamètre maximal au milieu (5) HUMM 5 & 19,0 & 19,0 & 23,0 & 22,5 \\
\hline Diamètre minimal au milieu (6) HUMM 6 & 16,0 & 16,0 & 18,0 & 18,0 \\
\hline Périmètre minimal (7) HUMM 7 & 56,0 & 55,0 & 67,0 & 65,0 \\
\hline Périmètre au milieu (7a) HUM M 7A & 58,0 & 55,0 & 67,0 & 65,0 \\
\hline Diamètre transversal de la tête (9) HUM M 9 & 37,0 & 37,0 & 47,0 & 45,0 \\
\hline Diamètre sagittal de la tête (10) HUM M 10 & 37,0 & 37,0 & 47,0 & 45,5 \\
\hline Indice de robustesse $(7 / 1)$ & 20,4 & 20,6 & 21,4 & 21,0 \\
\hline Indice de robustesse $(7 \mathrm{a} / 1)$ & 21,1 & 20,6 & 21,4 & 21,0 \\
\hline Indice diaphysaire $(6 / 5)$ & 84,2 & 84,2 & 78,3 & 80,0 \\
\hline Indice de la tête $(9 / 10)$ & 100,0 & 100,0 & 100,0 & 98,9 \\
\hline Radius & d & g & d & g \\
\hline Longueur maximale (1) RADM 1 & & 203,0 & 247,0 & 248,0 \\
\hline Longueur physiologique (2) RADM 2 & & 189,0 & 233,5 & 232,5 \\
\hline Périmètre minimal (3) RADM 3 & & 39,0 & 49,0 & 48,5 \\
\hline Diamètre transversal maximal de la diaphyse (4) RADM 4 & & 13,1 & 18,0 & 18,0 \\
\hline Diamètre sagittal de la diaphyse (5) RADM 5 & & 11,0 & 13,0 & 13,0 \\
\hline Indice de robustesse $(3 / 1)$ & & 19,2 & 19,8 & 19,6 \\
\hline Indice diaphysaire (5/4) & & 84,3 & 72,2 & 72,2 \\
\hline UIna & d & g & d & g \\
\hline Longueur maximale (1) ULNM 1 & 231,0 & 225,5 & 265,5 & 265,0 \\
\hline Longueur physiologique (2) ULNM 2 & 200,0 & 196,0 & 236,5 & 236,0 \\
\hline Périmètre minimal (3) ULNM 3 & 34,5 & 34,0 & 37,0 & 40,0 \\
\hline Diamètre sous-sigmoïdien transversal (13) U LN M 13 & 17,8 & 19,2 & 20,0 & 21,0 \\
\hline Diamètre sous-sigmoïdien sagittal (14) ULN M 14 & 22,0 & 22,7 & 24,0 & 25,0 \\
\hline Diamètre transversal maximal de la diaphyse (12) U LN M 12 & 13,4 & 12,8 & 18,0 & 18,5 \\
\hline Diamètre sagittal de la diaphyse (11) U LN M 11 & 12,0 & 12,2 & 15,0 & 15,0 \\
\hline Indice de robustesse $(3 / 1)$ & 14,9 & 15,1 & 13,9 & 15,1 \\
\hline Indice de robustesse $(3 / 2)$ & 17,3 & 17,3 & 15,6 & 16,9 \\
\hline Indice de platôlénie (13/14) & 81,1 & 84,4 & 83,3 & 84,0 \\
\hline Indice diaphysaire (11/12) & 89,6 & 95,3 & 83,3 & 81,1 \\
\hline
\end{tabular}

logie de cette anomalie reste discutée (Durward, 1929, cité par Kaufman et al., 1997), mais l'existence de plusieurs cas familiaux (H auser, De Stefano, 1989) permet d'envisager un 
déterminisme génétique légitimant sa prise en compte comme indicateurs des structures de parenté dans les études paléoanthropologiques (Crubézy, 1991a).

Son expression unilatérale chez le sujet B peut être considérée comme une forme atténuée de la lésion qui n'est

Tabl. V - Caractères métriques des membres inférieurs (les codes alpha-numériques correspon dent aux variables utilisées dans l'étude métrique comparative).

\begin{tabular}{|c|c|c|c|c|}
\hline \multirow{2}{*}{$\begin{array}{l}\text { O s et mesures en mm selon Martin } \\
\text { in Bräuer (1988) }\end{array}$} & \multicolumn{4}{|c|}{ Sujets } \\
\hline & Ind. B & Ind. A & Ind. A & sp.1020 \\
\hline Tibia & d & d & g & g \\
\hline Longueur totale (1) TIBIAM 1 & 312,0 & 350,0 & 362,0 & 308,0 \\
\hline Longueur maximale (1a) TIBIAM 1A & 315,0 & 365,0 & 364,0 & 314,0 \\
\hline Périmètre au milieu (10) TIBIAM 10 & 71,0 & 88,0 & 88,0 & 72,0 \\
\hline Périmètre minimal (10b) TIBIAM 10b & 67,5 & 79,1 & 82,5 & 64,5 \\
\hline Diamètre transversal au trou nourricier (9a) TIBIAM 9A & 20,2 & 24,5 & 24,0 & 19,0 \\
\hline Diamètre sagittal au trou nourricier (8a) TIBIAM $8 \mathrm{~A}$ & 29,0 & 36,5 & 38,0 & 30,5 \\
\hline Diamètre transversal au milieu (9) TIBIAM 9 & 18,0 & 21,0 & 22,0 & 18,0 \\
\hline Diamètre sagittal au milieu (8) TIBIAM8 & 26,0 & 33,0 & 34,0 & 26,0 \\
\hline Diamètre transversal extrémité proximale (3) TIBIAM 3 & 61,7 & 75,0 & 76,5 & 65,5 \\
\hline Diamètre transversal extrémité distale (6) TIBIAM 6 & 46,5 & 54,5 & 52,5 & 45,5 \\
\hline Indice de robustesse $(10 \mathrm{~b} / 1)$ & 21,6 & 22,6 & 22,8 & 20,9 \\
\hline Indice cnémique (9a/8a) & 69,8 & 67,1 & 63,2 & 62,3 \\
\hline Indice diaphysaire (9/8) & 69,2 & 63,6 & 64,7 & 69,2 \\
\hline Fémurs & d & d & g & g \\
\hline Longueur en position (2) FEM URM 2 & 379,0 & & 440,0 & 379,0 \\
\hline Longueur maximale (1) FEM URM 1 & 383,0 & & 444,0 & 372,5 \\
\hline Périmètre au milieu (8) FEMURM 8 & 74,5 & & 92,0 & 71,5 \\
\hline Diamètre sagittal au milieu (6) FEMURM 6 & 23,0 & & 33,0 & 22,3 \\
\hline Diamètre transversal au milieu (7) FEMURM 7 & 23,0 & & 26,0 & 23,0 \\
\hline Diamètre sous-trochantérien sagittal (10) FEM U RM 10 & 21,0 & & 27,5 & 18,8 \\
\hline Diamètre sous-trochantérien transversal (9) FEMU RM 9 & 29,5 & & 31,0 & 29,5 \\
\hline Diamètre vertical de la tête (18) FEM U RM 18 & 37,9 & & 47,0 & 39,0 \\
\hline Diamètre sagittal de la tête (19) FEM U RM 19 & 37,6 & & 47,0 & 38,5 \\
\hline Largeur bicondylienne (21) FEM U RM 21 & 67,0 & & 82,5 & 73,0 \\
\hline Indice de robustesse (8/2) & 19,7 & & 20,9 & 18,9 \\
\hline Indice de robustesse $(6+7 / 2)$ & 12,1 & & 13,4 & 11,9 \\
\hline Indice de platymérie (10/9) & 71,2 & & 88,7 & 63,6 \\
\hline Indice pilastrique (6/7) & 99,9 & & 126,9 & 96,9 \\
\hline Indice de la tête (19/18) & 99,2 & & 100,0 & 98,7 \\
\hline Indice de largeur bicondylienne (21/2) & 17,7 & & 18,8 & 19,3 \\
\hline
\end{tabular}

Tabl. VI - Estimation de la stature des individus de Narbons (exprimée en $\mathrm{cm}$ ).

\begin{tabular}{|c|c|c|c|c|}
\hline Sujets & Sexe & O s/côté & $\begin{array}{c}\text { Cleuvenot, Houët } \\
\text { (1993) }\end{array}$ & $\begin{array}{c}\text { Manouvrier } \\
\text { (1893) }\end{array}$ \\
\hline B & F & fémur d. & $148,7 \pm 4$ & 145,9 \\
\hline A & M & fémur g. & $168,4 \pm 4$ & 165,4 \\
\hline $\mathbf{1 0 2 0}$ & I & fémur g. & $149,2 \pm 4$ & $147,1(\mathrm{f}) ; 152,6(\mathrm{~m})$ \\
\hline
\end{tabular}

pas forcément symétrique (Ascenzi, 1980; Thillaud, 1983; Crubézy, 1991a). D'autre part le critère d'homologie topographique plaide en faveur d'une étiologie commune pour les deux sujets. On peut donc légitimement soupçonner un lien de parenté entre les individus A et B.

\section{ÉTUDE PALÉOPATHOLOGIQUE}

L'examen macroscopique de l'ensemble du squel ette du sujet $B$ de la sépulture 4000 n'a révélé aucune pathologie d'origine traumatique ou infectieuse. L'asymétrie des membres supérieurs (humérus) ne présente aucune justification pathologique apparente (absence de cal osseux ou de déviation de l'axe diaphysaire permettant un diagnostic de fracture): sans doute exprime-t-elle une latéralisation marquée.

Le crâne du sujet $A$ montre une perforation ovalaire (diamètre transversal $40 \mathrm{~mm}$, diamètre sagittal $20 \mathrm{~mm}$ ) à la partie supérieure de l'écaille occipitale, qui déborde sur le pariétal gauche. Un ébrasement endocrânien indique que la fracturation s'est opérée de l'extérieur vers l'intérieur. L'examen de la tranche de section révèle des arrachements de fragments de la lame interne inférieurs à $5 \mathrm{~mm}$. En revanche la lame externe ne présente ni un décollement, ni des lignes de fractures concentriques. Une fissure tangente à la partie inférieure de la perforation s'étend du frontal gauche à la région basi-occipitale. Une seconde fissure suit la suture lamdoïde gauche.

La différence de couleur existant entre les tranches de sections de la perforation et des fissures, montre l'antériorité de la première sur les secondes. Dès lors, les fissures ne peuvent correspondre à des lignes de fractures secondaires immédiatement consécutives à la perforation. Elles seraient plutôt le fait de la pression sédimentaire postdépositionnelle exercée sur le bloc crânien. II n'y a aucun indice de réaction périostée (cicatrisation) : la perforation est intervenue soit dans la période péri-mortem, soit plus tardivement; l'absence de trace de découpe ou de stries de grattage élimine le diagnostic de trépanation, et il n'existe aucun indice qui plaide en faveur d'une étiologie infectieuse.

L'hypothèse d'un traumatisme pourrait être envisagée, mais en l'absence de point d'impact sur le crâne et de fractures concentriques autour de la perforation, il est impossible de porter le diagnostic de fracture par objet contondant (Boulestin, 1998). Enfin, la faible dimension des décollements de la face interne est en faveur d'une fracturation intervenue sur os sec, c'est-à-dire après le décès. 

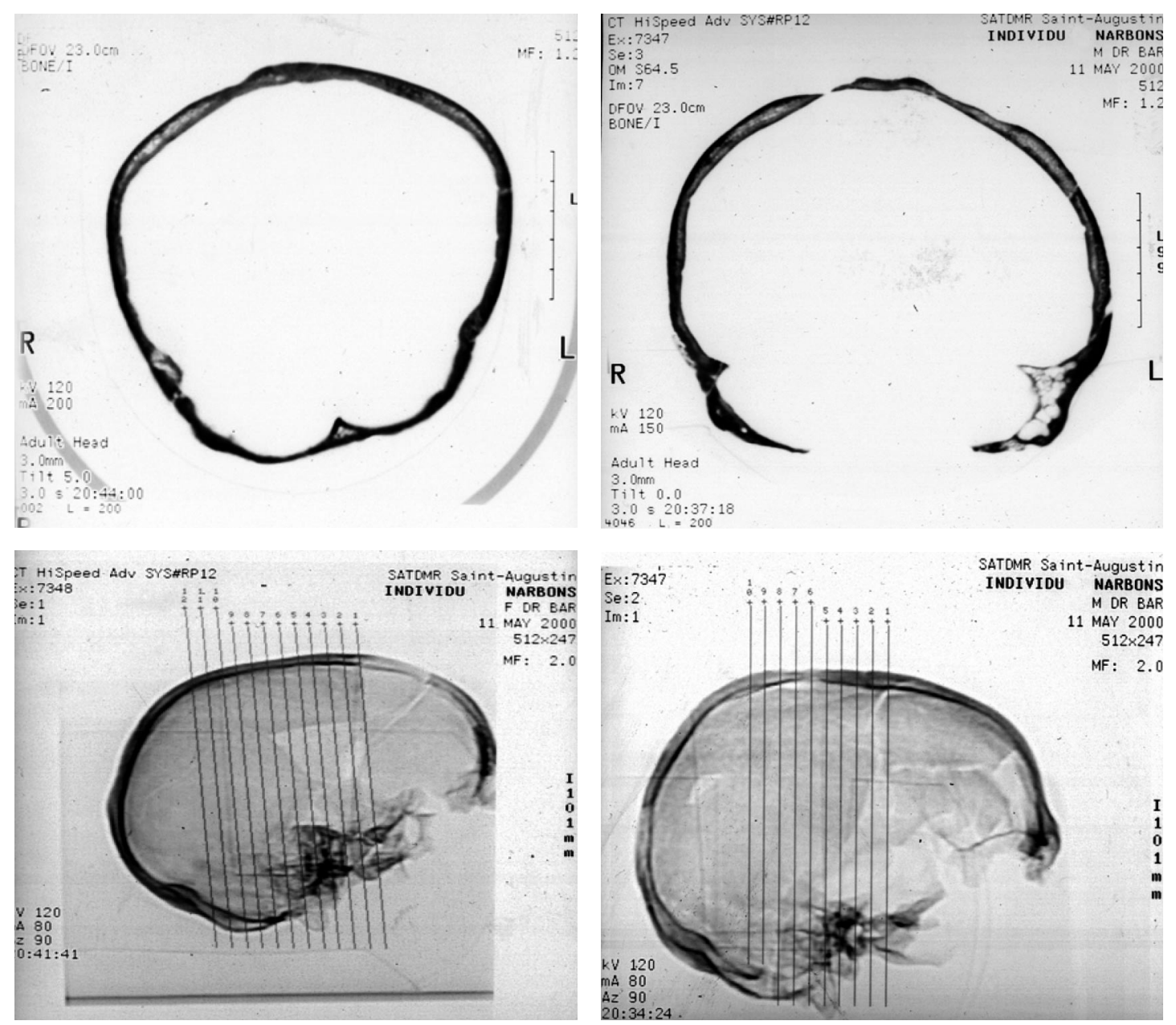

Fig. 21 - Sections frontales des crânes des sujets $B$ (à gauche) et $A$ (à droite).

Examens tomodensitométries: Dr D. Bars, radiologue, clinique Saint-A ugustin, Bordeaux.

L'examen des dents a révélé chez le même sujet, outre la présence de plusieurs caries et une forte usure dentaire, un kyste péri-apical de la seconde molaire du maxillaire gauche. D'origine carieuse, cette lésion a entraîné la destruction presque totale de la couronne dentaire et de la table vestibulaire. Le kyste se traduit également par un bombement de la paroi sinusienne avec, à son sommet, plusieurs orifices de diamètres inférieurs à un millimètre. Cette réaction périostée correspond à une fistulisation intra-sinusienne.

Le fait que la dent soit en place implique que le foyer infectieux était en phase évolutive au moment du décès. Les granulomes apicaux peuvent être à l'origine de complications généralisées: septicémie, embol septique endocrânien (Crubézy, 1988), et il n'est donc pas impossible que cette infection soit la cause indirecte du décès.

\section{LECTURE, COMPARAISONS ET INTERPRÉTATIONS}

En vue de l'analyse générale, la première question qui se pose concerne naturellement les relations spatiales et temporelles des sépultures néolithiques de $\mathrm{N}$ arbons.

En effet, le regroupement des tombes n'apparaît pas très clairement dans la mesure où les sépultures sont peu nombreuses par rapport à la superficie du site (quatre sur un demi-hectare). Elles sont séparées par des distances relativement importantes qui vont de $12,5 \mathrm{~m}$ jusqu'à $46,5 \mathrm{~m}$ et ne paraissent pas, en conséquence, vraiment organisées.

Morphologiquement, il faut relever que les fosses sont creusées dans la marne stampienne, très sensible à l'érosion, et qu'elles devaient toutes avoir une profondeur qui 
excédait notablement leur plus grande dimension en plan. Elles ont des parois régulières et subverticales. La seule variabilité qui s'exprime est le plan des structures 3067, qui est oblong, mais surtout celui de la structure 1020, qui est nettement circulaire. Ce sont les comblements sans doute assez rapides et la compacité de la marne encaissante qui expliquent probablement la régularité de ces structures, au moins à leurs bases. Les modifications de formes, éventuellement liées à une dégradation des parois, ne peuvent être suspectées que pour les parties supérieures des structures 1034 et 3035 qui sont les seules à révéler des comblements différenciés plus importants contre les parois qu'au centre.

\section{STYLE DU MOBILIER, ATTRIBUTION CULTURELLE ET POSITIONNEMENT CHRONOLOGIQUE}

Les deux fosses sans sépultures 3035 et 4002 sont attribuées au Néolithique à partir de plusieurs critères: morphologie semblable à celles qui contiennent des inhumations, présence d'une meule de type préhistorique en 3035, lots de restes de faune pouvant correspondre à un mode de traitement néolithique pour la fosse 4002. Ce sont évidemment des arguments fragiles et très imprécis, insuffisants pour envisager la possibilité d'une vraie synchronie avec les autres structures.

Les datations numériques des sépultures 3067, 1034 et $4000 \mathrm{~A}$ et $\mathrm{B}$ sont grosso modo concordantes et se situent dans la seconde moitié du cinquième millénaire avant notre ère. Leur marge haute peut empiéter sur les fourchettes admises pour les horizons du Préchasséen ou Protochasséen, tels qu'ils sont documentés par les ensembles de Camprafaud C14 ou de Font-Juvénal C11 en Languedoc occidental méditerranéen ou dans l'escargotière E5-2 de Villeneuve-Tolosane qui se placent au milieu et dans le troisième quart du cinquième millénaire (Vaquer, 1998). C'est la plage de probabilité maximale pour les sépultures 1034 et 3067, alors que la sépulture 4000 se placerait plutôt dans la seconde moitié du cinquième millénaire.

Leur marge basse (quatrième quart du cinquième millénaire) correspond au Chasséen ancien du style des Plots, tels qu'il est documenté dans les ensembles datés des Plots à Berriac (Aude), d'Auriac Golf à Carcassonne ou Encombres à Quarante, en Languedoc méditerranéen (Vaquer, Jédikian, 2003), ou du style chasséen garonnais des Monges daté dans la structure D4-7 de Villeneuve-Tolosane (François, Vaquer, 2000). Dans la mesure où ces trois struc- tures de Narbons n'ont pas livré de mobilier significatif, il est impossible de contrôler la fiabilité des datations radiométriques ou de préciser les attributions culturelles; c'est donc une plage chronologique assez large qu'il faut retenir pour ces trois sépultures.

La seule structure de Narbons pour laquelle le résultat de la datation peut être confronté à une série de mobilier est la fosse 1020. La série céramique issue de cette structure est assez restreinte mais comporte tout de même des éléments caractéristiques qui permettent une attribution au Chasséen méridional. Le nombre minimal de vases peut être établi à dix, les formes représentées sont les coupes en calotte, groupe ubiquiste généralement bien représenté dans les diverses étapes évolutives de cette culture, un vase à col haut et panse cordiforme avec bouton perforé qui représente une forme fréquente et très spécifique et un probable vase ovoïde à bouton perforé sous le bord d'un type plus rare mais signalé par exemple à La grotte de Seynes ou à la grotte de l'H ermitage à Alès dans le Gard ou dans la grotte de la Madeleine à Villeneuve-lès-M aguelonne dans I'H érault (Vaquer, 1975), et attesté plus récemment sur le site de Blagnat à Montmeyran dans la Drôme qui a pu être daté (A.A. 21721 Tucson: $5095 \pm 70$ BP, soit 4037-3708 av. J.-C.) (Saintot, 2002). On relève en plus les témoins de cinq autres individus aux formes indéterminables mais dont plusieurs portent des éléments de suspension: boutons perforés, barrettes biforées, tubulures verticales groupées qui sont assez typiques de cette culture. II faut noter toutefois les deux tessons d'un gros vase portant une languette de préhension insérée dans un décor de cannelures horizontales superposées disposées sur les joints de colombins d'un type inconnu dans les productions chasséennes, hormis peut-être dans certains ensembles biziens qui peuvent comporter des décors cannelés couvrants sur de gros vases, mais qui adoptent le plus souvent des dispositions en faisceaux avec des motifs curvilignes, en méandres, en vagues ou des motifs de lignes brisées en chevrons qui peuvent parfois être délimitées par des portées horizontales comme à Buzerens à Bram, Aude (Carozza, 1997), à la Petite grotte de Bize (Guilaine et al., 2001) ou à La Salle à Carcassonne, (Vaquer, Jédikian, 2003). Il faut noter toutefois que les décors biziens sont généralement plus fins que ceux de $N$ arbons et que ces derniers à cannelures assez larges et nettement séparées évoquent plutôt des productions qui se rencontrent généralement dans des horizons plus récents du Néolithique du Sud-O uest. On les connaît par exemple dans le Saint-Ponien de l'abri de Font-Juvénal à Conques-sur-O rbiel dans l'Aude 
où des surfaces ondulées dégagent de pseudo-cordons (Guilaine et al., 1980) ou dès la phase ancienne du groupe des Treilles par exemple dans la grotte de Sargel 1, SaintRome-de-Cernon dans I'Aveyron (Costantini, 1984) où des vases à cannelures multiples superposées sont une variante des jarres à cordons superposés si abondantes à cette époque. Ce type de décor est d'autre part très bien représenté dans le Crosien, groupe encore assez mal connu qui se place entre le Chasséen et l'Artenacien d'après les indications des stratigraphies de la grotte de La Perte du Cros à Saillac et celle de la grotte de Marsa à Beauregard, dans le Lot (Galan, 1961, 1967). Dans le premier gisement, la coexistence d'éléments du Chasséen final et du Crosien a été suggérée par les fouilleurs, mais aucun élément de type chasséen n'est attesté à Marsa, ce qui a conduit à critiquer l'association relevée sur le site éponyme et à l'interpréter comme résultant d'un mélange au contact de deux couches (Gernigon, 2000).

La coexistence de ces éléments dans le remplissage de la structure 1020 pose donc le problème de l'homogénéité de la série, d'autant que la datation obtenue sur les os de la sépulture se place au milieu du IVe millénaire (Ly-9669: $4705 \pm 50$ BP soit 3633 à 3369 av. J.-C., avec une probabilité maximale entre 3475 et 3369 av. J.-C. [ 49,2 \%]) ; elle est donc manifestement beaucoup plus récente que les autres. Dans ces conditions on peut envisager plusieurs hypothèses: soit la structure est chasséenne, mais elle n'était pas comblée entièrement ou bien elle a été recreusée pour recevoir une sépulture au Néolithique récent; soit la structure est du Néolithique récent, mais son comblement contient des éléments plus anciens en position secondaire, selon un cas de figure fréquent dans les structures remblayées; soit la structure rep résente un tout homogène attribuable à une étape de transition entre les deux époques, ce qui pourrait expliquer le style mixte de l'association observée.

L'aspect relativement bien conservé des parois de la fosse et la disposition en superposition horizontale des unités stratigraphiques permettent d'exclure la première hypothèse: en effet, contrairement à la structure 1034 du site de Narbons, aucune érosion suggérant que la structure ait pu rester longtemps ouverte et aucune anomalie dans la disposition des unités stratigraphique n'indiquent un recreusement. Enfin il faut rappeler que les deux tessons à décor cannelé ont été trouvés dans l'unité 3 en association avec le tesson à tubulures verticales typiquement chasséen, ce qui empêche d'envisager un comblement très lent de la structure à cheval sur les deux époques. Bien au contraire, la dispersion des tessons d'un des vases munis de barrettes biforées sur au moins trois unités stratigraphiques (US 5, 4 et 3 ) indique plutôt un comblement rapide. L'hypothèse selon laquelle le mobilier chasséen serait en position secondaire ne tient pas davantage dans la mesure où le vase à col est pratiquement entier, ce qui rend très peu plausible son intégration à un remblai provenant du remaniement de sédiments anthropisés plus anciens.

C'est donc la troisième hypothèse, celle d'une attribution à un Chasséen terminal, voire à un horizon en mutation vers le Néolithique récent qui semble la plus appropriée; elle mérite toutefois d'être examinée de plus près dans la mesure où les datations obtenues pour les autres structures de Narbons, malheureusement dépourvues de mobilier, se situent plutôt dans la plage chronologique des étapes anciennes du complexe chasséen. Sachant que les datations numériques disponibles sont loin de cadrer systématiquement avec les analyses des assemblages typologiques et les évidences stratigraphiques qui fondent les modèles de périodisation des styles céramiques, il convient dans ce cas de discuter la compatibilité entre la datation obtenue pour cette série et sa composition typologique. Plusieurs essais de périodisation des productions céramiques du Chasséen méridional ont été proposés à l'échelle régionale, qu'il s'agisse du Languedoc occidental méditerranéen (Vaquer, 1990a, 1991), du bassin de la Garonne (François, Vaquer, 2000) ou de la région des Grands Causses (Costantini, 1984). Si I'on se fie aux modèles présentés on peut exclure d'emblée toute attribution de la série de la structure 1020 à I'une des étapes anciennes du Chasséen de ces régions; en effet, la forme à col haut et panse cordiforme n'est jamais attestée dans les séries attribuables au cinquième millénaire, hormis le cas très douteux de la sépulture dite « royale » de Saint-Michel-du-Touch dont la position a été récemment réévaluée (François, Vaquer, 2000). Ce type de vase est souvent très bien représenté dans plusieurs horizons du Chasséen classique et récent, notamment à Auriac, Carcassonne (Aude) avec des exemplaires à un seul bouton perforé situé sur le renflement de la panse (Jédikian, 2000), ou dans les séries les plus récentes du Chasséen de Villeneuve-Tolosane et Cugnaux, et dans le Chasséen récent de style caussenard de La Perte du Cros. Cette même forme se trouve aussi dans les horizons récents d'autres régions comme sur le site de L'H éritière I à Vernègues (Bouches-duRhône) qui a fait l'objet d'une datation comparable à celle de Narbons (ETH 16883: $4810 \pm 65$ BP, soit 3775- 
3380 av. J.-C. avec des pics de probabilité entre 3710 et 3495 av. J.-C.) (Chapon et al., 2002).

Dans ces conditions, l'attribution du mobilier de la structure 1020 de Narbons à un stade terminal du Chasséen est très plausible même si la série est restreinte et dépourvue de vases carénés à mamelons non perforés ou couplés sur la carène qui semblent être les indicateurs les plus fiables pour reconnaître cette étape et I'horizon de transition avec le Néolithique récent. Ce marqueur existe notamment dans la couche 7 de la stratigraphie de référence de Font-Juvénal à Conques-sur-O rbiel (Guilaine et al., 1991) où il est associé à des fragments de vases à col haut et panse cordiforme surbaissée: I'un d'eux a le raccord col-panse souligné par une cannelure fine horizontale comme sur l'exemplaire de $N$ arbons. Ce vase est associé à une petite coupelle, décorée dans le style de Bize ou dans le style d'Auriac, qui porte un petit bouton perforé horizontalement sous le bord morphologiquement proche de celle de I'US 3. Ce type existe d'ailleurs aussi dans certains ensembles du Saint-Ponien comme celui de la grotte du Poteau à Saint-Pons, Hérault (Rodriguez et al., 1989). L a même couche 7 de Font-J uvénal a livré des fragments de barrettes perforées verticalement et un vase tulipiforme avec des grosses languettes reliées par un cordon lisse qui n'est pas sans évoquer les productions postérieures du Néolithique récent et final où l'on connaît des fragments de jarres à joints de colombins masqués par des cordons en relief superposés ou par des cannelures larges dégageant de faux cordons (notamment en C4). L'ensemble de la couche 7 de Font-Juvénal correspond au Chasséen récent et final du bassin de l'Aude; il comporte encore des éléments classiques de cette culture, mais commence à intégrer des éléments du Néolithique récent dans la céramique de grande capacité. II présente des affinités évidentes avec celui de Narbons, ses datations sont d'ailleurs très proches de celle de la structure 1020 (C7b, Ly-4775: $4760 \pm 140 \mathrm{BP}$, soit 3950-3050 av. J.-C. et C7a, MC 495: $4860 \pm 90 \mathrm{BP}$, soit 3950-3350 av. J.-C.).

II faut donc retenir que la datation obtenue pour la structure 1020 de Narbons est recevable au moins pour la partie la plus haute de la fourchette ( $d u 36^{\mathrm{e}}$ au $38^{\mathrm{e}}$ siècle) qui correspond bien à la fin du Chasséen. Si I'on retient comme valables les repères de chronologie numérique obtenus pour les autres structures du site, ce qui ne peut être contrôlé faute de mobilier, nous devons considérer que cette structure est beaucoup plus récente que celles dont les datations se situent dans la seconde moitié du cinquième millénaire av. J.-C.
II faut donc envisager que les quelques structures de Narbons peuvent s'étaler une très longue durée, plus d'un millénaire si l'on prend en compte les marges extrêmes des mesures et au moins sept cents ans si l'on se satisfait des moyennes. En outre, rien ne permet en plus d'affirmer que les structures non datées se situent vraiment dans ces plages de temps. Dans ces conditions, ce serait un pari bien risqué que de considérer les six structures néolithiques de Narbons comme faisant partie d'un ensemble homogène et il vaut sans doute mieux considérer qu'elles correspondent à au moins deux, voire plusieurs épisodes qu'il est bien difficile de cerner précisément. Les similitudes observées entre les diverses fosses et les pratiques funéraires pourraient en fait être liées à un biais taphonomique qui n'aurait laissé subsister sur le site que les structures les plus profondes, celles qui avaient à l'origine des vocations fonctionnelles similaires et qui ont pu recevoir secondairement des sépultures selon une tradition vivace et durable.

Quant au statut du site, il paraît plus que délicat de l'aborder sur la base d'un si petit nombre de structures conservées et de l'important écart chronologique entre la sépulture 1020 et les autres sépultures. Tout au plus est-il possible de dire que les fosses ont été détournées de leurs fonctions initiales, fonctions qui relèvent probablement de la sphère domestique. II n'est pas possible de préciser cependant si ces structures étaient vraiment implantées au sein d'un habitat ou dans sa périphérie directe. Seul le comblement de la structure la plus récente, 1020, qui recèle de nombreux tessons, pourrait trahir la proximité d'une activité domestique ou artisanale.

\section{STRUCTURES: DES SÉPULTURES EN PUITS?}

Le fait que les structures de Narbons aient gardé une profondeur notable alors qu'elles sont manifestement très arasées, leur répartition sur le rebord de la colline molassique et le fait qu'elles soient toutes creusées dans des marnes sableuses qui ont pu contenir un aquifère suspendu suggèrent qu'il puisse s'agir de puits.

L'existence de puits parfois très profonds dans le Néolithique moyen du Midi de la France n'est pas une nouveauté. Des structures de ce type ont été mentionnées sur plusieurs sites et semblent avoir eu plusieurs destinations. Sur le site de Giribaldi à Nice deux puits protochasséens ont été partiellement fouillés, I'un mesurait 1,5 m de diamètre et plus de $4 \mathrm{~m}$ de profondeur, l'autre beaucoup grand avait une forme oblongue et mesurait 3,5 $\mathrm{m}$ de grand 
axe pour près de $6 \mathrm{~m}$ de profondeur; ils sont interprétés comme des structures d'extraction d'argile destinée à la production de céramiques (Binder et al., 1994). Dans d'autres sites, la fonction de puits à eau est évidente car ces derniers atteignent des nappes phréatiques encore actives. C'était le cas à Villeneuve-Tolosane où un puits chasséen avait une forme cylindrique de $1,5 \mathrm{~m}$ de diamètre et 7,5 $\mathrm{m}$ de profondeur et traversait la terrasse graveleuse pour atteindre l'eau située à $7 \mathrm{~m}$ au moment de la fouille (Vaquer, 1990b). C'était le cas aussi sur le site de la gravière de Buzerens à Bram (Aude) où un puits rond de $2 \mathrm{~m}$ de diamètre et $1,3 \mathrm{~m}$ de profondeur sous le niveau de décapage atteignait une nappe phréatique actuelle très peu profonde, entre 0,8 et $1 \mathrm{~m}$, ce qui a permis la conservation de restes organiques à la base dans un milieu gorgé d'eau. Le matériel trouvé dans les $0,4 \mathrm{~m}$ supérieurs est très fragmenté mais caractéristique du groupe de Bize et daté: Ly-69 (O xa) 4860 \pm 60 BP, soit 3785-3511 av. J.-C. (Carozza, 1995, 1997).

On peut citer aussi le site de L'H éritière II à Vernègues (Bouches-du-Rhône) où les fouilles du TGV Méditerranée ont révélé un puits subcirculaire de $0,98 \mathrm{~m}$ de diamètre à l'embouchure avec élargissement vers la base jusqu'à 2,2 m (sans doute en raison de curages des effondrements de paroi). II mesurait 2,6 $\mathrm{m}$ de profondeur, la hauteur de la nappe phréatique actuelle étant à $1,8 \mathrm{~m}$; il a livré un abondant matériel qui se rapporte au Chasséen récent provençal daté (ETH 16883: $4810 \pm 65$ BP, soit 37753380 av. J.-C.) (Chapon et al., 2002). Un puits chasséen de $5,75 \mathrm{~m}$ de profondeur a été sondé mécaniquement par A. Vignaud dans le cadre d'une fouille préventive AFAN sur le site du Pont à Castelnau-le-Lez, H érault (Vignaud, 1998). D'autres puits chasséens non fouillés ont été signalés à $L a$ Roberte, Châteauneuf-du-Rhône, Drôme (Beeching, Thomas-Beeching, 1975) et à Barbentane, Bouches-duRhône (Sauzade, 1983). Enfin, il convient surtout de rappeler la publication ancienne d'un possible puits néolithique sur le site du Coustelet à Cabrières-d'Avignon, Vaucluse (Gagnière, Vareilles, 1931). Ce puits découvert dans le front d'exploitation d'une carrière avait une section horizontale circulaire de 0,9 m et une profondeur de 6,5 m. II contenait deux sépultures situées à des niveaux différents, l'une à $3,8 \mathrm{~m}$ et l'autre à $5,3 \mathrm{~m}$, il s'agissait d'individus inhumés en position repliée avec la tête vers l'est. Le mobilier trouvé est probablement chasséen, il comprend une lame en silex gris, des tessons de vases carénés et des restes de faune (maxillaire de chien et os de bovin) qui se trouvaient près des squelettes.
Les affinités avec $N$ arbons sont dans ce cas manifestes et documentent une pratique qui est attestée aussi dans certains des autres puits que nous avons mentionnés. Dans le puits de l'H éritère II, une sépulture se trouvait à 2,2 $\mathrm{m}$ de profondeur : il s'agissait d'un individu féminin en décubitus latéral gauche qui se serait décomposé en espace confiné; il était accompagné par le crâne et une mandibule d'un autre individu. Le mobilier comporte des fragments de meules et deux vases entiers dont un vase à col haut et panse cordiforme pratiquement identique à celui de Narbons. À Barbentane, l'inventeur du puits a montré à G. Sauzade des éléments qui témoignent sans doute de la présence d'une sépulture chasséenne (restes humains, notamment des fragments de calotte crânienne, avec des fragments d'écuelles, des lames et lamelles de silex, des billes). À Villeneuve-Tolosane, l'étude des restes osseux du puits qui est en cours a révélé au sein de la faune la présence de restes humains attribuables à un fœtus.

Finalement, ces informations tendent à révéler que la pratique consistant à établir des sépultures dans le comblement de puits désaffectés, sans être systématique, est tout de même récurrente dans le Midi de la France au Néolithique moyen; en effet, sur les neuf puits mentionnés, quatre ont livré des restes d'inhumations; cette proportion pourrait même être plus élevée puisque trois sur les quatre fouillés entièrement en ont livrés. II nous paraît donc logique de retenir en priorité cette hypothèse pour les structures de Narbons.

\section{RESTES DE FAUNE}

Si l'on consulte la littérature, on note que les différents types de vestiges fauniques de Narbons (1020, 3035, 4002) ont aussi été observés à maintes reprises dans des tombes du Chasséen méridional. Ces comparaisons impliquent une réflexion relative à la signification, symbolique ou non, des dépôts. En effet, doivent-ils être considérés comme des rejets de consommation ordinaires contenus dans les sédiments ou sur le fond des fosses? Ou bien ont-ils un statut plus directement lié à la symbolique funéraire (offrande, reliefs de repas)?

À ce propos, les observations réalisées sur les sépultures chasséennes du Gournier près de Montélimar (Drôme) sont très enrichissantes (Beeching, 2003; Beeching, Crubézy, 1998) car elles concernent la mise en évidence d'associations récurrentes entre des dépôts humains et des vestiges de faune (principalement du bœuf), dans une même fosse 
ou dans plusieurs structures différentes. Au sujet de possibles offrandes « dissociées », on peut mentionner la sépulture de Montbeyre-la-Cadoule, dans I'Hérault (Laboucarie, Arnal, 1989), où des restes crâniens de boviné et un fragment de maxillaire ont été retrouvés au-dessus d'un squelette de nourrisson. II reposait lui-même à l'aplomb d'un hémi-calvarium de boviné, déposé sur le fond de la fosse.

On peut aussi s'interroger sur le rôle des animaux « déposés » entiers, tels que le suidé (4002) et peut-être le blaireau (3067). Au-delà de la notion d'offrande, dissociée ou en association stricte, l'éventualité de l'existence de véritables sépultures animales a même été proposée par l'un d'entre nous (Vaquer, 1998, p. 168) . En domaine garonnais, cette faune possède généralement un statut domestique ou semi-domestique (jeune suidé, chiens). Le blaireau de la fosse 3067 évoquerait, quant à lui, davantage le renard présent dans I'une des sépultures de «Cami de Can Grau » (Marti i Rosell et al., 1997; Pou i Calvet, Marti i Rosell, 1999), mais il n'est pas certain qu'il ait fait l'objet d'un dépôt.

\section{DÉFUNTS}

Le nombre restreint des individus exhumés limite considérablement le champ interprétatif. En outre, l'adulte de la sépulture 1020 est assurément plus récent. Plusieurs classes d'âge (adultes et immatures) y sont représentées, ainsi que les deux sexes (tabl. I). L'examen paléopathologique des deux individus de la sépulture 4000 n'a pas révélé de lésion osseuse commune permettant d'éclairer les raisons de leurs décès. L'exercice de la paléopathologie sur le squelette n'autorisant qu'une approche ostéoarticulaire et odontologique, ces résultats sont forcément partiels. On notera cependant que le décès de l'homme (sujet $A, 4000$ ), qui a été disposé le premier, pourrait être lié à une atteinte carieuse. Pour cette sépulture, I'analyse des caractères discrets a mis en évidence la présence d'une anomalie anatomique rare, l'amincissement pariétal circonscrit de la voûte crânienne, qui laisse présumer l'existence d'un lien de parenté.

\section{PRATIQUES FUNÉRAIRES}

Les pratiques funéraires du Néolithique moyen de l'aire occitano-catalane sont très diversifiées et relèvent aussi bien de la tradition des tombes en contexte d'habitat dans des structures spécifiques ou réaffectées, que de nécropoles de tombes en fosse, de proto-hypogées ou de monuments enterrés et aériens à appareillage lithique en coffre (Vaquer, 1998).

Le préalable à toute réflexion est de tenter de déterminer le caractère funéraire des dépôts, détermination qui n'est jamais aisée pour les ensembles domestiques méridionaux. En vue de cette reconnaissance, les faits les plus lisibles sont la variété de la population inhumée et les soins apportés au cadavre, à son agencement, à sa protection. La question de la fonction initiale des fosses, longtemps au centre du débat, est probablement assez secondaire pour la reconnaissance du caractère funéraire lui-même. En effet, devant cet apparent foisonnement d'expressions, c'est surtout l'observation non-sélective des faits gravitant autours des défunts, et de leur répétition, qui demeure fondamentale en vue d'approcher leur pertinence.

À Narbons, les sépultures présentent de nombreuses variations entre elles, concernant les positions et orientations, mais aussi une certaine homogénéité, concernant la situation des dépôts ( tabl. VII). Le cas le plus particulier est indéniablement celui de l'individu de la fosse cylindrique 1020, qui est également le plus récent de l'occupation néolithique. En effet, l'absence d'un « véritable » agencement du corps, son décentrement et le colmatage immédiat de I'espace, l'apparentent davantage à un élément du comblement, comme cela a déjà été envisagé pour certains individus des sites drômois ( Beeching, 2003, p. 232). Ce fait le distingue nettement des autres dépôts, pour lesquels une procédure d'agencement du corps est constante.

La sépulture double 4000 est la plus singulière, avec ses deux individus disposés simultanément sur le ventre, dans un espace très contraignant, puis protégés par un dispositif rigide semi-perméable. Les positions sur le ventre n'ont pas été souvent observées et le fait qu'elles découlent d'un agencement n'est pas toujours évident. On peut mentionner la sépulture de Lavimona à Cugnaux, en Haute-Garonne (Nacfer, 1991, p. 65), une autre sépulture de ce site qui concerne un immature ( sépulture 2; Brossier et al., 2000) , la sépulture 36 des Plots, à Berriac (Duday, Vaquer 2003) qui se rapporte au Chasséen ancien, et quatre sépultures des ensembles drômois plus récents du Gournier et de SaintPaul-Trois-Châteaux (Beeching et al., 1987; Beeching, 1991, 2003; Crubézy, 1991b; Beeching, Crubézy, 1998). Les deux enfants de Narbons ont été déposés sur le côté gauche, bien au centre de la fosse. Les orientations dominantes sont ouestest, tête à l'ouest ( 3 sur 4), l'individu 1020 ne pouvant être comptabilisé car sa position ne relève pas d'un agence- 
Tabl. VII - Tableau récapitulatif des assemblages de N arbons.

\begin{tabular}{|c|c|c|c|c|c|c|}
\hline & Fosse 3035 & Fosse 4002 & Fosse 1034 & Fosse 3067 & Fosse 4000 & Fosse 1020 \\
\hline Morphologie & $\begin{array}{l}\text { Plan sup. oblong } \\
(1 \mathrm{~m} \times 1,3 \mathrm{~m}) \\
\text { Plan inf. rectangulaire } \\
\text { Prof. conservée } 1,7 \mathrm{~m}\end{array}$ & $\begin{array}{l}\text { Plan subrectangulaire } \\
(0,7 \mathrm{~m} \times 1,2 \mathrm{~m}) \\
\text { Prof. conservée } 1,1 \mathrm{~m}\end{array}$ & $\begin{array}{l}\text { Plan subrectangulaire } \\
(0,9 \mathrm{~m} \times 1,2 \mathrm{~m}) \\
\text { Prof. conservée } 1,5 \mathrm{~m}\end{array}$ & \begin{tabular}{|l} 
Plan oblong \\
$(0,85 \mathrm{~m} \times 1,2 \mathrm{~m})$ \\
Prof. conservée $0,9 \mathrm{~m}$
\end{tabular} & $\begin{array}{l}\text { Plan subrectangulaire } \\
(0,7 \mathrm{~m} \times 1,4 \mathrm{~m}) \\
\text { Prof. conservée } 1,6 \mathrm{~m}\end{array}$ & $\begin{array}{l}\text { Plan circulaire } \\
(0,7 \mathrm{~m} \emptyset) \\
\text { Prof. conservée } 1,2 \mathrm{~m}\end{array}$ \\
\hline Comblement (s) & $\begin{array}{l}\text { Assez homogène, } \\
\text { rapidement mis en place }\end{array}$ & $\begin{array}{l}\text { Assez homogène, } \\
\text { rapidement mis en place }\end{array}$ & $\begin{array}{l}\text { Deux dynamiques majeures, } \\
\text { séquence supérieure plus } \\
\text { progressive }\end{array}$ & $\begin{array}{l}\text { Trois séquences } \\
\text { principales, la première } \\
\text { semble la plus progressive }\end{array}$ & Deux séquences? & $\begin{array}{l}\text { Trois séquences principales: } \\
\text { rejets de combustion sur le } \\
\text { fond ; une grande séquence } \\
\text { rapide riche en mobilier ; } \\
\text { une séquence stérile qui } \\
\text { enveloppe le défunt }\end{array}$ \\
\hline Fonction initiale & Puits désaffecté & Puits désaffecté & Puits désaffecté & Puits désaffecté? & Puits désaffecté & Puits désaffecté? \\
\hline Individu (s) & 0 & 0 & $\begin{array}{l}\text { Un jeune enfant } \\
(0,5-1 \text { an) }\end{array}$ & $\begin{array}{l}\text { Un enfant } \\
\text { (7,5-9,5 ans) }\end{array}$ & $\begin{array}{l}\text { Deux adultes, } \mathrm{F} \text { et } \mathrm{M} \\
\text { avec lien de parenté }\end{array}$ & Un adulte gracile \\
\hline Situation & 0 & 0 & Dans le comblement & Dans le comblement & Dans le comblement & Dans le comblement \\
\hline Position (s) & 0 & 0 & $\begin{array}{l}\text { Côté gauche, } \\
O-E\end{array}$ & $\begin{array}{l}\text { Fléchi côté gauche, } \\
\text { SO-NE }\end{array}$ & $\begin{array}{l}\text { Sur le ventre, } \\
\text { membres fléchis 0-E }\end{array}$ & $\begin{array}{l}\text { Fléchi, contraint } \\
\text { contre la paroi NE-SO }\end{array}$ \\
\hline Espace de dépôt & 0 & 0 & Confiné? & Confiné & Confiné & Colmaté \\
\hline $\begin{array}{l}\text { Datations } \\
\text { absolues }\end{array}$ & 0 & 0 & $\begin{array}{l}\text { (Gra-16249, Ly-1157): } \\
5440 \pm 80 \text { BP, soit } \\
4451 \text { à } 4045 \text { av. J.-C. }\end{array}$ & $\begin{array}{l}\text { (Gra-16247, Ly-1158): } \\
5470 \pm 60 \text { BP, soit } \\
4455 \text { à } 4054 \text { av. J.-C. }\end{array}$ & $\begin{array}{l}\text { Ly } 9668: 5310 \pm 40 \mathrm{BP}, \\
\text { soit } 4248 \text { à } 3997 \text { av. J.-C. } \\
\text { Ly } 11373: 5470 \pm 50 \mathrm{BP}, \\
\text { soit } 4449 \text { à } 4168 \text { av. J.-C. }\end{array}$ & $\begin{array}{l}\text { Ly } 9669: 4705 \pm 50 \text { BP, } \\
\text { soit } 3633 \text { à } 3369 \text { av. J.-C. }\end{array}$ \\
\hline $\begin{array}{l}\text { Mobilier } \\
\text { céramique }\end{array}$ & 0 & 0 & 0 & 0 & 0 & $\begin{array}{l}\text { Riche en rejets, dans les } \\
\text { séquences inférieures. } \\
\text { Un vase sur le fond au-dessus } \\
\text { des reliquats de combustion }\end{array}$ \\
\hline Faune & Cerf (hémimandibule) & \begin{tabular}{|l|} 
Suidé ( 2 ind. imm.), \\
dont 1 en connection. \\
Au fond de la fosse, \\
boviné, 1 juvénile, \\
sous-repr. dont les restes \\
sont groupés
\end{tabular} & $\begin{array}{l}\text { Un bois de cerf, } \\
\text { probablement en situation } \\
\text { d'offrande sépulcrale }\end{array}$ & $\begin{array}{l}\text { Une canine de suidé } \\
\text { refendue et polie, parure } \\
\text { (ass. au défunt ?). } \\
\text { Un blaireau en connection } \\
\text { sur le fond de fosse }\end{array}$ & 0 & $\begin{array}{l}\text { Riche en rejets dans les } \\
\text { séquences inférieures. } \\
\text { Les restes se rapportant à } \\
3 \text { bovinés; } 11 \text { suidés ; } \\
1 \text { capriné ; } 1 \text { cerf ; } 1 \text { chien. }\end{array}$ \\
\hline Mobilier autre & Meule & 0 & 0 & 0 & 0 & 0 \\
\hline $\begin{array}{l}\text { Attribution } \\
\text { culturelle }\end{array}$ & Néolithique & Néolithique & $\begin{array}{l}\text { Préchasséen ou } \\
\text { Chasséen ancien }\end{array}$ & $\begin{array}{l}\text { Préchasséen ou } \\
\text { Chasséen ancien }\end{array}$ & $\begin{array}{l}\text { Préchasséen ou } \\
\text { Chasséen ancien }\end{array}$ & Chasséen final \\
\hline Statut du dépôt & $\begin{array}{l}\text { Rejets ponctuels en } \\
\text { cours de comblement? }\end{array}$ & Dépôts animaliers? & $\begin{array}{l}\text { Sépulture dans } \\
\text { structure réaffectée }\end{array}$ & $\begin{array}{l}\text { Sépulture dans } \\
\text { structure réaffectée }\end{array}$ & $\begin{array}{l}\text { Sépulture dans } \\
\text { structure réaffectée }\end{array}$ & Rejets ou dépôts funéraires? \\
\hline
\end{tabular}

ment. Pour les trois structures se rattachant à l'occupation ancienne, un dispositif de protection du cadavre a pu être attesté (4000, 3067), ou envisagé (1034).

Dans les documents comparatifs, la nature des espaces de décomposition est variée. Les dépôts en «pleine terre », majoritaires, côtoient toujours d'autres dépôts, isolés des sédiments (Vaquer, Duday, 1989; Boujot et al., 1991, p. 414). Les aménagements peuvent d'ailleurs se révéler d'une grande complexité, et des observations en faveur de contenants semi-rigides ont été effectuées à six reprises sur les sites du Midi (Vaquer, 1998, p. 172). Dans ce domaine géographique, les sépultures multiples demeurent rares (tombe 7 de Villeneuve-Tolosane; Vaquer, 1990a, p. 247). À ce propos, et concernant les autres thèmes abordés, la documentation funéraire du Chasséen ancien méridional va se retrouver singulièrement renouvelée grâce aux nombreuses sépultures fouillées sur le site du Crès près de Béziers dans l'H érault ( Loison et al., 2003).

L'individu féminin 4000B de Narbons était très contraint et occupait un espace moindre que le premier défunt disposé. II pourrait simplement s'agir d'une contrainte technique, la fosse étant profonde et l'espace réduit, mais le thème de l'individu «central » mérite d'être évoqué. En effet, la situation « privilégiée » de certains individus a pu être discernée, notamment dans la vallée du Rhône, pour des adultes des deux sexes (Beeching, 1991, p. 337-338). On s'accorde souvent pour y déceler une des manifestations de la transition vers les tombes « collectives » (Boujot et al., 
1991) où les premiers morts peuvent symboliquement organiser l'espace sépulcral. Dans le cas de la sépulture 4000, la cause du décès du premier défunt peut être suspectée au regard de son état dentaire: il s'agit probablement d'une septicémie. Pour la défunte qui l'accompagne, aucun indice relatif à son décès n'a pu être observé sur les os. Par contre, ils portent l'empreinte d'une anomalie trahissant un lien de parenté. II n'est malheureusement pas possible d'en saisir le degré, ni bien sûr de qualifier le lien social sans doute à l'origine de ce dépôt qui est simultané, mais relève probablement d'une planification. Au-delà, cette stratégie soulève la question relative au statut de la défunte dans la tombe; celle-ci n'était peut-être qu'une accompagnante, voire une offrande.

Pour trois des quatre individus se rapportant au Chasséen ancien (1034, 3067, 4000A), la volonté d'accomplir un geste sépulcral est en revanche explicite. Elle permet donc de qualifier les dépôts et, au-delà, de discuter plus avant le statut funéraire ou opportuniste des fosses profondes ayant accueilli les défunts. Ce qui nous questionne surtout dans l'optique de cette définition, c'est la position récurrente des individus au sein des comblements. En effet, l'intentionnalité de la mise en place des séquences inférieures n'est pas évidente, même si elles ont dû rendre les dépôts indéniablement plus commodes. C'est le cas de l'une des sépultures récemment fouillées à Cépie près de Limoux dans l'Aude (Tchérémissinoff, 2003b). Elle concerne un enfant soigneusement disposé sur une première séquence de comblement, au centre de la fosse, à I'instar de l'enfant 3067 de Narbons. Quoi qu'il en soit, les comparaisons indiquent que la mise en place des comblements ne correspond généralement pas à un abandon prolongé de la structure, ce qui plaide donc plutôt en faveur du détournement volontaire des fosses.

Cette question est aussi déterminante quant à la définition des éléments mobiliers présents dans les fosses et à leur éventuelle relation à la sépulture. C'est d'ailleurs un problème qui se pose fréquemment dans les assemblages méridionaux et qui ne peut être éludé par la simple constatation d'une absence d'association formelle. En effet, de nombreux liens symboliques peuvent être suspectés à travers des mises en scène, comme c'est le cas du bris de céramique à Berriac (Vaquer, 1998; Duday, Vaquer 2003), et elle peut aussi être appréhendée à travers la présence récurrente de certains types d'objets fonctionnels (Jallot et al., 2000). Pour les ensembles rhodaniens, A. Beeching (2003, p. 237) souligne le souci d'une scénarisation des différents dépôts, qui présentent des constantes et doivent probablement se décrypter à l'échelle du site et en regard de sa vocation funéraire. Dans ce cadre, il s'interroge sur le statut d'éléments pouvant être assimilés à des rejets détritiques, dans une perspective d'association à d'autres dépôts. L'une des illustrations de la complexité de cette définition à Narbons, est sans doute les curieux « rejets » du fond de la fosse 1020, qui incluaient un vase à col, une forme déjà remarquée en association avec des défunts, par exemple à Saint-M ichel-du-Touch (M éroc, 1962; M éroc, Simonet, 1979, p. 397) ou à Villeneuve-Tolosane (Vaquer, 1991, p. 35-36; 1998, p. 183). II reposait de manière subverticale au-dessus d'un amas de faune, coloré consécutivement à une combustion qui s'est déroulée à proximité, voire au sein même de la fosse. Cet ensemble était surmonté par une séquence riche en tessons, qui s'est rapidement mise en place et enrobait par ailleurs un défunt.

Les éléments brûlés et les traces de chaleur sont également fréquents, voire peut-être constitutifs dans les manifestations funéraires en fosse du Midi. Le site d'habitat des Plots, à Berriac, qui recelait 6 défunts dans une même fourchette temporelle que celle des individus 1304, 3067 et 4000, a ainsi livré des rejets très particuliers. Dans I'une des fosses, un adulte se trouvait sur le ventre, excentré, au sein d'une séquence cendreuse. De nombreux tessons avaient été rejetés en plusieurs niveaux du remplissage, qui ne correspondaient en fait qu'à une seule séquence. Ces tessons, qui présentaient de nombreux collages avec ceux contenus dans une fosse voisine et avaient été très altérés, voire fondus, par le feu en un autre lieu, ont suggéré aux auteurs I'hypothèse d'un rite de destruction du mobilier du défunt (Vaquer, Duday, 1989; Vaquer, 1998, p. 182-183; Duday, Vaquer, 2003, p. 73, 78). Cette configuration se retrouve sur le site des Perreiras à Pouzols dans l'Aude, où les tombes 3 et 4 contenaient de nombreux éléments brûlés (Ambert et al., 1989, p. 31) et pour lequel il est même fait mention de foyers intermédiaires (Duday, Guilaine, 1975, p. 144). Un niveau d'argile très cuite recouvrait aussi la sépulture d'enfant déjà évoquée de Cépie, Aude (Tchérémissinoff, 2003b). Ce niveau était lui-même surmonté d'un amas de galets, pouvant peut-être constituer un marquage.

$$
\text { * } *
$$

À Narbons, l'aspect qui touche à la diversité des personnes inhumées est perceptible, malgré le petit nombre de sépultures. En effet, les trois sépultures anciennes, possiblement contemporaines, concernent chaque fois un 
individu de type différent (une femme, un homme, un enfant et un jeune enfant), traduisant une absence de critères reliés à l'âge ou au sexe dans le recrutement: c'est-à-dire conforme à ce que l'on attend d'un ensemble funéraire. Évidemment, le caractère spécifiquement funéraire du site paraît peu envisageable, mais là n'est pas la question.

On peut ainsi constater à Narbons que les fosses n'ont pas été initialement destinées à recevoir des défunts - il s'agit probablement de puits - mais que leur détournement a probablement été codifié. En effet, les procédures liées à l'agencement et à la protection des corps des structures 1034, 3067 et 4000A, caractérisent bien la nature sépulcrale de ces dépôts. Le fait que toutes ces sépultures soient installées au sein des comblements ne paraît pas faire obstacle à cette définition. En effet, s'il est impossible d'établir le caractère intentionnel de leur mise en place, il est peu probable que les fosses soient restées ouvertes des années, en regard de la nature de l'encaissant. Si cela avait été le cas, dans I'hypothèse d'un cuvelage interne, il nous semble que les comblements auraient eu une composante plus anthropique ou tout au moins plus organique. Par ailleurs, ces premières séquences sédimentaires ont dû rendre les dispositions des corps plus commodes dans des structures de grande profondeur. En conséquence, elles ne sont pas incompatibles avec une procédure de réaffectation planifiée. À ce propos, trois corps au moins ont fait l'objet d'une procédure d'isolement des sédiments $(3067,4000)$ : ils ne sont donc clairement pas assimilés à de simples restes.

Concernant les différents mobiliers, seule la présence du bois de cerf, au même niveau que la sépulture 1034, et la canine de suidé, près de la mandibule de 3067, permettent d'argumenter en faveur de leur statut d'offrande funéraire.
En termes d'association, il convient également d'évoquer I'individu B, de la sépulture 4000, qui est peut-être lui-même en position d'accompagnant, voire d'offrande. Concernant les rejets de types détritiques (1020), les multiples comparaisons possibles démontrent que la prudence doit être de mise en vue de leur définition. Cette remarque s'applique aussi à certains dépôts «périphériques » ou « dissociés » particuliers, comme les animaux complets en connexion, si souvent remarqués dans des contextes équivalents.

\section{Remerciements}

Nous tenons à remercier chaleureusement Frédéric Guédon (INRAP), ainsi que toute l'équipe de fouille de Narbons, en particulier Béatrice Boisseau, Anne Lagarrigue, Patricia Mornais et Christian Vallet. Nous remercions aussi les intervenants administratifs et scientifiques, JeanChristophe Bats, (INRAP), Henri Duday (UMR 5809 du CNRS), Sylvie Riuné-Lacabe (directrice interrégionale INRAP Grand-Sud-O uest), Michel Vaginay (conservateur régional de l'Archéologie de Midi-Pyrénées) et Jacques Jaubert (conservateur régional adjoint), sans lesquels cette présente publication n'aurait pu être réalisée dans les bonnes conditions dont nous avons bénéficié. Toute notre gratitude va également à nos amis et collègues, Yann Beliez, pour la traduction du résumé, Claire Manen et Philippe Chambon pour les relectures et à Laurent Loiselier pour la qualité des dessins illustrant cet article. Pour l'encadrement de l'étude biologique, nous tenons également à remercier Henri Duday (directeur de recherche CNRS-UMR 5809), qui a dirigé le DEA de Myriam Texier, dont I'analyse paléobiologique est issue. Merci enfin au docteur Dominique Bars, radiologue à la clinique Saint-Augustin de Bordeaux, qui a réalisé les examens tomodensitométriques. 


\section{BIBLIOGRAPHIE}

Ambert P., Genna A., Taffanel 0.

1989 : « Contribution à l'étude du Chasséen du Minervois », in Le Chasséen en Languedoc oriental. Hommage à Jean Arnal, Actes des journées d'études, M ontpellier, 25-27 oct. 1985, Université Paul Valéry, département de Préhistoire, 1, p. 25-36.

Ascenzi A.

1980 : «Données microscopiques comparatives sur l'atrophie dite symétrique des pariétaux », Paleopathology Association, $3^{\text {th }}$ European Meeting, Caen, $257 \mathrm{p}$.

\section{Beeching A.}

1991 : « Sépultures, territoire et société dans le Chasséen méridional. L'exemple du Bassin rhodanien », in BEECHING A. Binder D., Blanchet J.-C. et al. (Dir.), Identité du Chasséen, Actes du colloque international de Nemours 1989, Nemours, éd. APRAIF (Mémoires du musée de Préhistoire d'Île-de-France, 4) , p. 327-341.

2003 : « Organisation spatiale et symbolique du rituel funéraire chasséen en moyenne vallée du Rhône: première approche », in Chambon P., LeCLeRC J. (ÉD.), Les pratiques funéraires néolithiques avant 3500 av. J.-C. en France et dans les régions limitrophes, Table ronde de la Société préhistorique française Saint-Germain-en-Laye, 15-17 juin 2001, Paris, SPF ( Mémoires de la Société préhistorique française, XXXIII), p. 231-239.

Beeching A., Crubézy E.

1998 : « Les sépultures chasséennes de la vallée du Rhône », in GuILAINE J. (ÉD.), Sépultures d'Occident et genèse des mégalithismes (9000-3500 avant notre ère), Séminaire du Collège de France sous la direction de Jean Guilaine, Paris, éd. Errance, p. 147-164.

Beeching A., Crubézy E., Cordier F.

1987 : «Les sépultures chasséennes de SaintPaul-Trois-Châteaux (Drôme) », in Sépultures nélithiques, Actes des rencontres néolithiques de RhôneAlpes, Centre d'archéologie préhistorique de Valence, 3 , p. 21-30.

Beeching A., Thomas-Beeching J.

1975 : « L'habitat chasséen de la Roberte à Châteauneuf-du-Rhône », Études préhistoriques, 12 , p. 23-32.

Binder D., Gassin B., Sénepart I.

1994 : «Éléments pour la caractérisation des productions céramiques néolithiques dans le sud de la France. L'exemple de Giribaldi », in BINDER D., COURTIN J. (DIR.) Terre cuite et société: la céramique, document technique, économique et culturel, Actes des XIVe rencontres internationale d'archéologie et d'histoire d'A ntibes, 21-23 oct. 1993, Juan-lesPins, éd. APDCA, p. 255-267.

Boujot C., Crubézy E., Duday H.

1991 : «L'identité du Chasséen à travers les structures et pratiques funéraires », in Beeching A., Binder D., Blanchet J.-C. et al. (DIR.), Identité du Chasséen, Actes du colloque international de Nemours 1989, Nemours, éd. APRAIF (Mémoires du musée de Préhistoire d'île-de-France, 4), p. 413-420.

\section{BOULESTIN B.}

1998 : A pproche taphon omique des restes humains. L e cas des mésolithiques de la grotte des Perrats (Agris, Charente), thèse de doctorat, spécialité Anthropologie, univ. Bordeaux-I, $298 \mathrm{p}$.

\section{Braüer G.}

1988 : « O stéométrie ». in KnUSSMAnN R. (ÉD.), Anthropologie, handbuch der vergleichenden Biologie des M enschen, Band I, Wesen und methoden der Anthropologie, Auflage des Lehrbuchs des Anthropologie begrundet von R. Martin, Gustav Fisher Verlag, p. 160-232.

Brossier S., Lelouvier L.-A., Marlière P., Marty P., Vidaillet F., Bouby L., Carrère l., Cayn P., Gaudin E., Servelle C.

2000 : «Le site chasséen de VilleneuveTolosane / Cugnaux, Haute-Garonne: une nouvelle opération de sauvetage (1996-1997) 》, in LEDUC M., Valdeyron N., Vaquer J. (Éd.), Sociétés et espaces, Actes des rencontres méridionales de Préhistoire récente, $3^{\mathrm{e}}$ session, Toulouse, 6-7 nov. 1998, Toulouse, éd. Archives d'écologie préhistorique, p. 313-318.

BruzeK J.

1992 : «Fiabilité des fonctions discriminantes dans la détermination sexuelle de l'os coxal. Critiques et propositions», Bulletins et $M$ émoires de la Société d'anthropologie de Paris, n. s., 4, 1-2, p. 67-104.

\section{Camps-Fabrer $\mathbf{H}$.}

1979 : « L'industrie osseuse néolithique de l'abri Jean Cros», in Guilaine J. (Éd.), L'abri Jean Cros, Toulouse, Centre d'anthropologie des sociétés rurales, p. 185-196.

CAROZZA L.

1995 : «Buzerens (Bram, Aude) Structure du Néolithique moyen ", in Guilaine J., Ambert P., Barthès P., Vaquer J. et al. (ÉD.), Temps et espace dans le Bassin del'Aude du Néolithique à l'âge du Fer, ATP: grands projets d'archéologie métropolitaine, Toulouse, Centre d'anthropologie des sociétés rurales, p. 38-41.

1997 : «Un puits chasséen du groupe de Bize sur le site de Bram Buzerens », in Guilaine J., Barthès P. (Éd.), La PosteVieille, Toulouse, Centre d'anthropologie des sociétés rurales / Carcassonne, Archéologie en Terre d'Aude, p. 201-205.

\section{CAstex D.}

1994 : M ortalité, morbidité et gestion de l'espace funéraire au cours du $\mathrm{H}$ aut $M$ oyen $A g e$, thèse de doctorat, univ. Bordeaux-I, $329 \mathrm{p}$.

Chapon P., hasler A., Renault S., Villemeur I.

2002 : «Le site chasséen de l'Héritière II à Vernègues (Bouches-du-Rhône) » in Archéologie du TGV M éditerranée, Fiches de synthèse, t. 1, La Préhistoire, Fiche 19, Lattes (Monographie d'archéologie méditerranéenne, 8), p. 203-212.

\section{Cleuvenot E., Houët $F$.}

1993 : «Proposition de nouvelles équations d'estimation de la stature applicables pour un sexe indéterminé et basées sur les échantillons de Trotter et Gleser », Bulletins et $M$ émoires de la Société d'anthropologie de Paris, n. s., 5, p. 245-255.

\section{Costantini G.}

1984 : «Le Néolithique et le Chalcolithique des Grands Causses », Gallia Préhistoire, 27, fasc. 1, p. 121-210.

\section{Crubézy E.}

1988 : Interactions entre facteurs bio-culturels, pathologie et caractères discrets. Exemple d'une population médiévale: Canac (Aveyron), thèse de doctorat, univ. Montpellier-I, fac. de médecine, $444 \mathrm{p}$.

1991a: Caractères discrets et évolution. Exemple d'une population nubienne: Missiminia (Soudan), thèse de doctorat, univ. Bordeaux-1, $473 \mathrm{p}$. 
1991b: «Les pratiques funéraires dans le Chasséen de la moyenne vallée du Rhône », in BEECHING A., BINDER D., BLANChet J.-C. et al. (DIR.), Identité du Chasséen, Actes du colloque international de Nemours 1989, Nemours, éd. APRAIF ( Mémoires du musée de Préhistoire d'Îlede-France, 4), p. 391-398.

Duday H., Guilaine J.

1975 : « Les rites funéraires en L anguedoc et Roussillon du Néolithique au premier âge du Fer », Cahiers ligures de préhistoire et d'archéologie, 24, p. 141-151.

\section{Duday H., Vaquer J.}

2003 : «Les sépultures chasséennes du site des Plots, Berriac (Aude) », in ChAmBon L., LECLERC J. (ÉD.), Les pratiques funéraires néolithiques avant 3500 av. J.-C. en France et dans les régions limitrophes, Table ronde de la Société préhistorique française, Saint-G ermainen-Laye, 15-17 juin 2001, Paris, SPF (Mémoires de la Société préhistorique française, $X X X \mid I I$ ), p. 73-79.

François P., Vaquer J.

2000 : «Essai de périodisation des productions céramiques du Chasséen garonnais », in LEDUC M., VALDEYRon N., VAquer J. (ÉD.), Sociétés et espaces, Actes des rencontres méridionales de Préhistoire récente, $3^{\text {e }}$ session, Toulouse 6-7 nov. 1998, Toulouse, éd. Archives d'écologie préhistorique, p. 319-327.

\section{Galan A.}

1961 : « La grotte de Marsa (Beauregard, Lot) », Gallia Préhistoire, IV, p. 91-131.

1967 : «La station néolithique de la Perte du Cros à Saillac (Lot) », Gallia Préhistoire, X, p. 1-60.

\section{Gagnière S., Vareille L.}

1931 : «Le puits funéraire néolithique de Coustelet à Cabrières-d'Avignon (Vaucluse) 》, Cahiers d'histoire et d'archéologie, Nîmes, Larguier, I, p. 113-117.

Geddes D., Carrère l., Alzieu J.-P.

1987 : «Découpe des bovins au Néolithique moyen à Villeneuve-Tolosane », Anthropozoologica, $\mathrm{n}^{\circ}$ spécial $\mathrm{La}$ découpe et le partage du corps à travers l'espace, Actes de la table ronde, 14-15 nov. 1985, Paris, p. 97-106.

\section{Gemmerich Pfister I.}

1999 : Création d'une collection anthropologique de référence et application des caractères discrets dans le cas de généalogies connues, thèse de doctorat, spécialité Anthropologie, univ. de Genève, $266 p$.

\section{Gernigon K.}

2000 : «La céramique chasséenne du Querçy et les stratigraphies régionales », in Leduc M., Valdeyron N., Vaquer J. (éd.), Sociétés et espaces, A ctes des ren contres méridionales de Préhistoire récente, $3^{\mathrm{e}}$ session, Toulou se 6-7 nov. 1998, Toulouse, éd. Archives d'écologie préhistorique, p. 329-335.

\section{GUÉDON F.}

1999 : « Montesquieu-Lauragais. Narbons », Bilan scientifique Midi-Pyrénées, Toulouse, Service régional de l'Archéologie, p. 216-217.

\section{Guédon F., Vallet C.}

1999 : Le site de Narbons, DFS de Sauvetage urgent, Toulouse-Pamiers, AFAN Travaux A 66, Toulouse, Service régional de I'Archéologie.

Guilaine J., Amiel C., Barthès P., Coularou J., Vaquer J.

1991 : «Le Chasséen de l'Abri de FontJuvénal », in Guilaine J., Gutherz X., Autour de J. Arnal, Montpellier, éd. Recherches sur les premières communautés paysannes, p. 163-175.

Guilaine J., Coularou J., Briois F.

2001 : «Bizien de Bize. Du Monde des chasseurs à celui des métallurgistes ", Revue archéologique de l'O uest, supplément $n^{\circ}$ 9, p. 247-265.

Guilaine J., Vaquer J., Gasco J., Barrié P.

1980 : « Le Néolithique récent-final et le Chalcolithique de I'abri Font-Juvénal (Aude) », in Guilaine J. (ÉD.), Le groupe de Véraza et la fin des temps néolithiques dans le M idi de la France et la Catalogne, Colloque de Narbonne2, 1977, Toulouse, éd. du CNRS, p. 13-16.

Hauser G., De Stefano G. F.

1989 : Epigenetic variants of the human skull, Schweizerbart-Stuttgart, $301 \mathrm{p}$.

\section{HEIM J.-L.}

1963 : «Les apophyses geni, étude anthropologique », Bulletins et $M$ émoires de la Société d'anthropologie de Paris, $4, n^{\circ} 1$, série $X I$, p. $585-658$.

Jallot L., Georjon C., Wattez J., Blaizot F., LÉa V., Beugnier V.

2000 : «Principaux résultats de l'étude du site chasséen ancien de Jaques Cœur II (Port-
Marianne, Montpellier, Hérault) », in Leduc M., Valdeyron N., Vaquer J. (Éd.), Sociétés et espaces, Actes des Rencontres méridionales de Préhistoire récente, $3^{e}$ session, Toulouse 6-7 nov. 1998, Toulouse, éd. Archives d'écologie préhistorique, p. 281-303.

\section{JÉDIKIAN G.}

2000 : « Typologie de la céramique chasséenne: l'exemple du site d'Auriac », in Leduc M., Valdeyron N., Vaquer J. (ÉD.), Sociétés et espaces, Actes des rencontres méridionales de Préhistoire récente, $3^{\mathrm{e}}$ session, Toulouse 6-7 nov. 1998, Toulouse, éd. Archives d'écologie préhistorique, p. 305-311.

Kaufman M. H., Whitaker D., Mc Tavish J.

1997 : «Differential diagnosis of holes in the calvarium: Application of modern clinical data to palaeopathology », Journal of Archaeological Science, 24, p. 193-218.

Laboucarié S., Arnal G.-B.

1989 : «La sépulture chasséenne (L.IV) du gisement de Montbeyre-la-Cadoule à Teyran (Hérault) », Archéologie en Languedoc, 4, p. 27-33.

Loison G., Villemeur l., Fabre V.

2003 : «Structures domestiques et aménagements funéraires sur le site chasséen du Crès à Béziers ( H érault) », A rchéopages, 10, p. 32-39.

Majó T., Tillier A.-M, Bruzek J.

1993 : « Test des fonctions discriminantes de Schutkowski impliquant l'ilium pour la détermination du sexe dans des séries d'enfants de sexe et d'âge connus », Bulletins et $M$ émoires de la Société d'anthropologie de Paris, n. s. 5, Croisance et vieillissement, A ctes du $21^{\mathrm{e}}$ colloque du Groupement des anthropologistes de langue fran çaise, p. 61-68.

Manouvrier L.

1893: «La détermination de la stature d'après les grands os des membres », M émoires de la Société d'anthropologie de Paris, 4, p. $347-402$.

Marti I Rosel M., Pou I Calvet R., Carlus I Martin $X$.

1997 : La necrópolis del neolític mitjà i les restes romanes del Camí de Can Grau, (La Roca del Vallès, Vallès oriental) - Els jaciments de Cal Jardiner (Granollers, Vallès oriental) Barcelona, Generalitat de Catalunya, departament de Cultura, $235 \mathrm{p}$. 
Méroc L.

1962 : «L L village et la sépulture chasséens de Villeneuve-Tolosane (H aute-Garonne, France) », Zephyrus, XIII, p. 94-98.

Méroc L., Simonnet G.

1979 : «Les sépultures chasséennes de SaintMichel-du-Touch, à Toulouse (H auteGaronne) », Bulletin de la Société préhistorique fran çaise, 76, 10-12, p. 379-407.

1981 : «Objets mobiliers insolites en terre cuite et en os du Néolithique chasséen de Saint-Michel-du-Touch à Toulouse (Haute-Garonne) », in La Préhistoire du Qu ercy dans le con texte de M idi-Pyrénées, A ctes du congrès préhistorique de France, XXIe session, Montauban-Cahors, 1979, vol. 1, p. 223-233.

Moorees C. F. A., Fanning E. A., Hunt E. E.

1963a: «Formation and resorption of three deciduous teeth in Children », American Journal of Physical Anthropology, 21, p. 205-213.

1963b: «Age variation of formation stages for ten permanent teeth », Journal of Dental Research, 42 (6) , p. 1490-1502.

\section{Murail P.}

1996 : Biologie et pratiques funéraires des populations d'époque historique: une démarche méthodologique appliquée à la nécropole galloromaine de Chantambre, thèse de doctorat, univ. Bordeaux-I, $267 \mathrm{p}$.

Murail P., Bruzek J., Braga J.

1999 : «A new approach to sexual diagnosis in past populations. Practical ajustments from Van Vark's Procedure », International Journal of Osteoarchaeology, 9, p. 39-53.

\section{NACFER M.-N.}

1991 : «Cugnaux: Lavimona ». Bilan scientifique régional de Midi-Pyrénées, Toulouse, Service régional de l'Archéologie, p. 63-65, 2 fig.

\section{O Wings-Webb P. A., Suchey J. M.}

1985 : «Epiphyseal union of the anterior iliac crest and medial clavicle in a modern multiracial sample of American males and females », American Journal of Physical Anthropology, 68, p. 457-466.

\section{Pou i Calvet R., Marti I Rosel M.}

1999 : El Cami de Can Grau. La Roca del Vallès. Una necropolis de sepultures en fossa del neolític mitjà, Barcelona, Generalitat de Catalunya, departament de Cultura, 31 p.
RiQuet R.

1970 : Anthropologie du N éolithique et du Bronze ancien, Poitiers, éd. Texier, $280 \mathrm{p}$.

Rodriguez G., Marsac P., Erroux J.

1989 : « Le niveau saintponien de la grotte du poteau, Saint-Pons ( Hérault) », Archéologie en Languedoc, 4, $\mathrm{H}$ ommage à $\mathrm{H}$ enri Prades, p. $57-71,14$.

\section{Saintot S.}

2002 : « La maison chasséenne du site de Blagnat à Montmeyran », in Archéologie du T GV M éditerranée, Fiches de synthèse, t. $1, \mathrm{La}$ Préhistoire, Fiche 1, Lattes, Monographie d'archéologie méditerranéenne, 8, p. 20-22, 2.

\section{SAUNDERS S. R.}

1978 : The Development and Distribution of Discontinuous M orphological Variation of the Human Infracranial Skeleton, Ottawa, National Museum of Man (Archaeological Survey of Canada, paper 81), $549 \mathrm{p}$.

SAUZADE G.

1983 : Les Sépultures du Vau cluse du Néolithiqueà l'âge du Bronze, Paris, éd. du Laboratoire de Paléontologie humaine et de Préhistoire (Études quaternaires, mém. 6), $256 \mathrm{p}$.

\section{TCHÉRÉMISSINOFF Y.}

2003a: "Les sépultures chasséennes de Narbons (H aute-Garonne): description, comparaisons et fonctionnemente », in Chambon P., LeCLeRC J. (Éd.), Les pratiques funéraires néolithiques avant 3500 av. J.-C. en France et dans les régions limitrophes, Table ronde de la Société préhistorique française, Saint-Germain-en-Laye, 15-17 juin 2001, Paris, SPF ( Mémoires de la Société préhistorique française, $X X X I I I$ ), p. 81-89.

2003b: «Deux nouvelles sépultures néolithiques dans la région de Limoux (Aude)», in Chambon P., LeClerc J. (Éd.), Les pratiques funéraires nélithiques avant 3500 av. J.-C. en France et dans les régions limitrophes, Table ronde de la Société préhistorique française, Saint-Germain-en-Laye, 15-17 juin 2001, Paris, SPF (Mémoires de la Société préhistorique française, XXXIII), p. 185-189.

TChérémissinoff Y., avec la collab. de Boisseau B., Guédon F., Lagarrigue A., Mornais P., Pont-Tricoire C., Vallet C. 2000 : «Les sépultures chasséennes du site de Narbons (H aute-Garonne). Actualités »,
Bulletin de la Sociéé préhistorique française, 97, 4, p. 663-665.

\section{THILLAUd P.-L.}

1983 : «Paléopathologie des amincissements de la voûte crânienne: à propos des "trépanations incomplètes" en Égypte Pharaonique (nécropole d'Aksha, Mirgissa et Soleb) », L'Anthropologie, 87, 4, p. 499-519.

Vallois H.-V.

1948 : «Techniques anthropométriques », La semaine des Hôpitaux de Paris, 24, p. $374-383$.

\section{VAQUER J.}

1975 : La Céramique chasséenne du Languedoc, éd. du Laboratoire de préhistoire et de palethnologie de Carcassonne, $368 \mathrm{p}$.

1990a: Le Néolithique en Languedoc occidental, Paris, éd. du CNRS, $398 \mathrm{p}$.

1990b: «L'évolution du Chasséen méridional, essai dans le bassin de l'Aude », in Autour de J. Arnal, Montpellier, éd. Recherches sur les premières communautés paysannes, p. 177-189, 5 fig.

1991 : « Aspect du Chasséen en Languedoc occidental, $\mathrm{H}$ abitat et culture matérielle », in Beeching A., Binder D., Blanchet J.-C. et al. (DIR.), Identité du Chasséen, Actes du colloque international de Nemours 1989, Nemours, éd. APRAIF (Mémoires du musée de Préhistoire d'Île-de-France, 4), p. 27-37.

1998 : «Les sépultures du Néolithique moyen en France méditerranéenne », in Guilaine J. (ÉD.), Sépultures d'Occident et gen èse des mégalithismes (9000-3500 avant notre ère), Séminaire du Collège de France sous la direction de Jean Guilaine, Paris, éd. Errance, p. 167-186.

Vaquer J., Duday H.

1989 : «L'énigme des sépultures néolithiques de Carcassonne », La recherche, 20, 206, p. 130-131.

VAQUer J., Jédikian G.

2003 : "La Salle, Carcassonne (Aude). Un habitat de plein air du groupe de Bize», Bulletin de la Société préhistorique française, 100,2 , p. 323-351, 23 fig.

\section{Vignaud A.}

1998 : «Castelnau-le-Lez, Le Pont », Bilan scientifique régional de la région $L$ anguedocRoussillon, Montpellier, Service régional de l'Archéologie, p. 96. 